\title{
Social Deprivation of Infant Rhesus Monkeys Alters the Chemoarchitecture of the Brain: I. Subcortical Regions
}

\author{
Lee J. Martin, ${ }^{1,2}$ Dawn M. Spicer, ${ }^{2}$ Mark H. Lewis, ${ }^{4}$ John P. Gluck, ${ }^{5}$ and Linda C. Cork ${ }^{1,3}$ \\ ${ }^{1}$ Department of Pathology, ${ }^{2}$ Neuropathology Laboratory, and ${ }^{3}$ Division of Comparative Medicine, The Johns Hopkins \\ University School of Medicine, Baltimore, Maryland 21205, ${ }^{4}$ Department of Psychiatry, and Brain and Development \\ Research Center, The University of North Carolina, Chapel Hill, North Carolina 27514, and ${ }^{5}$ Department of Psychology, \\ The University of New Mexico, Albuquerque, New Mexico 87106
}

Rhesus monkeys (Macaca mulatta) reared during the first year of life without social contact develop persistent stereotyped movements, self-directed behaviors, and psychosocial abnormalities, but neurobiological mechanisms underlying the behaviors of socially deprived (SD) monkeys are unknown. Monkeys were reared in total social deprivation for the first 9 months of life; control monkeys were reared socially (SR) with mothers and peers. Subjects were killed at 19-24 yr of age. Because the behaviors of SD monkeys are reminiscent of changes in striatal or amygdalar function, we used immunocytochemistry for substance P (SP), leucine-enkephalin (LENK), somatostatin, calbindin, and tyrosine hydroxylase (TH) to evaluate qualitatively and quantitatively patterns of neurotransmitter marker immunoreactivity within subcortical regions. In SD monkeys, the chemoarchitecture of the striatum was altered. Neuronal cell bodies and processes immunoreactive for SP and LENK were depleted markedly in patch (striosome) and matrix regions of the caudate nucleus and putamen; the average density of SP-immunoreactive neurons was reduced $58 \%$ relative to SR monkeys. Calbindin and TH immunoreactivities were diminished in the matrix of caudate and putamen of SD monkeys. THimmunoreactive neurons, but not cresyl violet-stained neurons, in the substantia nigra pars compacta were decreased $(43 \%)$ in SD monkeys. Peptide-immunoreactive terminals were reduced in the globus pallidus and substantia nigra in SD monkeys. The nucleus accumbens was the least affected of striatal regions. Striatal somatostatin immunoreactivity was qualitatively and quantitatively similar in SD and SR monkeys. Several regions, for example, bed nucleus of the stria terminalis, amygdala, and basal forebrain magnocellular complex, that were in the same sections and are enriched in these markers did not appear altered in SD monkeys, suggesting a regional specificity for vulnerability. The altered chemoarchitecture of some basal ganglia regions in adult monkeys that experienced social deprivation as infants suggests that the postnatal maturation of neurotransmitter phenotypes in some structures is influenced by social en-

Received Jan. 25, 1991; revised May 21, 1991; accepted June 13, 1991.

We thank Ann Hester Price and Judy Van Lare for their technical assistance. This work was funded by Grants RR00130, NS 20471, and ADRC AG05146 and MH42938 from the U.S. Public Health Services, National Institutes of Health.

Correspondence should be addressed to Lee J. Martin, Ph.D., The Johns Hopkins University School of Medicine, Neuropathology I aboratory, 509 Pathology Building, 600 North Wolfe Street, Baltimore, MD 21205-2181.

Copyright (C) 1991 Society for Neuroscience $0270-6474 / 91 / 113344-15 \$ 05.00 / 0$ vironment. Abnormal motor and psychosocial behaviors resulting from this form of social/sensory deprivation may result from alterations in peptidergic and dopaminergic systems within the basal ganglia.

Rhesus monkeys (Macaca mulatta) that have experienced social deprivation for extended periods during the first year of infancy devclop abnormal motor and social bchaviors (Mitchell, 1970; Harlow et al., 1971; Prescott, 1971; Goosen, 1981; Suomi, 1982; Kraemer, 1985) (Table 1), including stereotyped locomotion and gross rhythmic stereotypic movements, fearfulness, social withdrawal, inappropriate reproductive and maternal behavior, learning deficits, and self-directed behavior (e.g., self-huddling and self-injurious behaviors of varying intensity). Without intensive resocialization soon after the isolation period, early social deprivation can have devastating, prolonged effects on primate behavior that persist into adulthood (Mitchell, 1970; Harlow et al., 1971; Prescott, 1971; Goosen, 1981; Suomi, 1982; Kraemer, 1985). Thus, it is likely that these behaviors reflect structural and functional modifications in the brain (Prescott, 1971; Hubel, 1978). Environmental effects on postnatal brain development have been established in studies of visual deprivation and subsequent development of the visual system (Hubel, 1978). However, only a few Golgi studics (Riesen et al., 1977; Struble and Riesen, 1978; Floeter and Greenough, 1979) have attempted to define neuropathologic changes in the brains of socially deprived (SD) primates.

This report defines some of the effects of early postnatal social deprivation on the brains of nonhuman primates. Brains obtained for this study were from SD monkeys that showed major dimensions of the isolate syndrome in adulthood, and the behaviors persisted virtually unchanged. The social competencies of the SD and socially reared (SR) monkeys described here were assessed in group living situations, and then attempts were made to modify the social deficits of these isolate monkeys (Frank, 1979). While these SD monkeys tolerated some passive social interaction, more complex forms of social reciprocity were strikingly absent. Moreover, the stereotyped behavior displayed by these SD monkeys hampered interactions with socially competent subjects. Other studies on the SD monkeys described here documented increased errors when the animals had to select the odd object of a set of three objects (Gluck et al., 1973), increased perseveration on a task following nonreward (Gluck and Sackett, 1976), inability to ignore redundant or irrelevant stimuli (Beauchamp and Gluck, 1988; Beauchamp et al., 1991), persistence of self-injurious behavior (Gluck and Sackett, 1974; 
Gluck et al., 1985), and perturbations in dopamine and dopamine-regulated functions (Lewis et al., 1990).

SD rhesus monkeys manifest abnormalities in social and affective function (Table 1), as well as stereotypic movements and evidence of dopamine receptor supersensitivity (Lewis et al., 1990); thus, we examined initially subcortical forebrain structures (e.g., striatum and amygdala) because these regions have been implicated in affect, mood, motivation, and stereotypic movements (Stevens, 1973; Alexander et al., 1986; Scheel-Krugcr, 1986). These structures are complex, chcmically hetcrogcneous regions with integral compartments that differ in neurotransmitter composition and connections (Graybiel and Ragsdale, 1978, 1983; Beckstead et al., 1979; Haber and Elde, 1982; Beach and McGeer, 1984; Crutcher and DeLong, 1984; Gerfen, 1984; Gerfen et al., 1985; Haber, 1986; Berendse et al., 1988; DeLong et al., 1988; Ragsdale and Graybiel, 1988; Hadfield et al., 1989; Langer and Graybiel, 1989). Moreover, the striatum and amygdala undergo changes in neurotransmitters and neurotransmitter receptors postnatally to achieve the adult pattern of organization (Liozou, 1972; Olson et al., 1972; Tennyson et al., 1972; Graybiel et al., 1981; Bachevalier et al., 1986; Nastuk and Graybiel, 1989; Sirinathsinghji and Dunnett, 1989). We used immunocytochemistry to test the hypothesis that the formation of chemoarchitectonic patterns within the forebrain of adult nonhuman primates was influenced by early social deprivation. Our results show that social deprivation of nconatal rhesus monkeys alters development of normal adult patterns of immunoreactivity for monoaminergic and neuropeptidergic transmitter markers within the striatum and some associated basal ganglia regions. Furthermore, the striatum appears to be more at risk than the amygdala and other basal forebrain regions. We hypothesize that the striatum may be more vulnerable because of its connectional organization and rate of postnatal maturation.

\section{Materials and Methods}

Male $(n=2)$ and female $(n=2)$ rhesus monkeys were reared in total isolation. The definition of terms and paradigms and detailed descriptions of housing conditions have been reviewed previously (Mitchell, 1970; Harlow et al., 1971; Goosen, 1981; Suomi, 1982; Kraemer, 1985). Total isolation involved separating infant monkeys from mothers no later than hours after birth and rearing them singly for 9 months in an enclosed, opaque, stainless-steel chamber $(60 \times 60 \times 60 \mathrm{~cm})$ that prevented visual and tactile contact with conspecifics. For the first $20 \mathrm{~d}$ after birth, SD monkeys experienced limited handling for feeding, but after this period no handling was experienced. Control subjects were rhesus monkeys socially reared (SR) with their mother and peers $(n=$ 5) (i.e., infants reared in group housing with mothers) or feral $(n=2)$ monkeys that matured in the wild. Housing conditions for SD and SR monkeys were identical after the first 9 months of life. Monkeys in SD and SR groups participated previously in tests of learning, cognition, social behavior, stereotyped behavior, and self-injurious behavior. The SD monkeys used in this study displayed abnormal reactions to noxious stimuli, deficits in response inhibition, slower adaptation to reinforcement contingencies, lower performance on oddity tasks, atypical cognitive processing, increased eye blink rate evoked by apomorphine, and increased rates of stereotyped and self-injurious behaviors (Sackett, 1972a; Beauchamp and Gluck, 1988; Lewis et al., 1990). All monkeys were 19-24 yr of age when killed.

Monkeys were restrained with ketamine, anesthetized with an overdose of pentobarbital, and perfused transcardially with cold $0.9 \%$ saline. Brains were cut stereotaxically; coronal blocks (1 cm thick) were immersion fixed $\left(8 \mathrm{hr}\right.$ at $\left.4^{\circ} \mathrm{C}\right)$ in $5 \%$ acrolein (Aldrich, Milwaukee, WI)

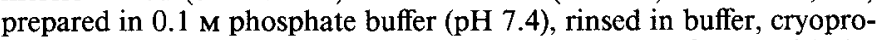
tected (overnight at $4^{\circ} \mathrm{C}$ ) in buffered $20 \%$ glycerol, and frozen with dry ice. Frozen sections $(40 \mu \mathrm{m})$ were cut coronally through the entire extent of the striatum and processed in a series of six to eight sections per
Table 1. Abnormal motor and psychopathologic behaviors of SD monkeys ${ }^{a}$

Stereotyped locomotion and gross rhythmic movements

Circling

Somersaulting

Pacing

Swaying

Abnormal social behaviorts

Fearfulness

Withdrawal

Lack of play

Apathy and indifference to external stimuli

Deficiencies in communication

Aggressivencss

Abnormal self-directed behaviors

Oral fixations

Huddling

Self-injury

Autoeroticism

Abnormal reproductive behaviors

Failure to establish normal heterosexual relations

Deficits in display and orientation for copulation

Abnormal maternal behaviors

Indifference

Abusiveness

${ }^{a}$ Abnormal motor and psychopathological behaviors of isolation reared monkeys have been well documented (Mitchell, 1970; Harlow et al., 1971; Prescott, 1971; Goosen, 1981; Suomi, 1982; Kraemer, 1985).

rotation, including sections for histological stains (cresyl violet, and hematoxylin and eosin) and immunocytochemical localization of neuropeptides, calbindin, and tyrosine hydroxylase $(\mathrm{TH})$. Tissues were prepared for immunocytochemistry using polyclonal antisera to leucineenkephalin (LENK) and somatostatin-28 and monoclonal antibodies to substance P (SP), calcium-binding protein (calbindin), and TH. Dilutions and sources of primary antisera are shown in Table 2. Immunohistochemical specificity of primary antibody was established by substituting antiserum with normal, nonimmune rabbit serum or mouse IgG used at comparable dilutions, and by preabsorption of antisera with an excess of synthetic antigen (Sigma).

All sections were processed free floating utilizing an indirect peroxidase-antiperoxidase (PAP) technique. Because visualization of immunoreactive neuronal cell bodies and processes may depend on the immunocytochemical protocol employed (Graybiel and Chesselet, 1984), we compared three variations, designated protocols $\mathrm{A}, \mathrm{B}$, and $\mathrm{C}$, in immunocytochemical processing of brain sections. Brain sections from age-matched SD and SR monkeys were always processed simultaneously regardless of protocol, and subsequent comparisons were made only between similarly processed sections. Immunocytochemical procedures were performed at $4^{\circ} \mathrm{C}$ unless otherwise specified.

For protocol A, $0.05 \mathrm{~m}$ Tris-buffered saline (TBS; $1.5 \% \mathrm{NaCl}$ ) was used. Sections were pretreated $(10 \mathrm{~min})$ sequentially with $0.1 \mathrm{M}$ sodium metaperiodate-TBS and $1 \%$ sodium borohydride-TBS to reduce residual aldehydes. Sections were treated with $0.4 \%$ Triton X-100 (Tx)-TBS (30 min), preincubated ( $1 \mathrm{hr}$ ) in $4 \%$ normal goat serum (NGS) or $10 \%$ nonfat dry milk/0.2\% Tx-TBS, and subsequently incubated ( $48 \mathrm{hr})$ in primary antisera diluted in $0.1 \% \mathrm{Tx}-\mathrm{TBS} / 2 \% \mathrm{NGS}$ or $5 \%$ milk. Following primary antibody incubation, sections were rinsed and incubated (1 hr) with appropriate affinity-purified secondary $\operatorname{IgG}$ (i.e., goat anti-rabbit or goat anti-mouse; Cappel), diluted $1: 100$ in $0.1 \%$ Tx-TBS $/ 2 \%$ NGS or $5 \%$ milk. Sections were rinsed and incubated $(1 \mathrm{hr})$ with the appropriate PAP complex (i.e., rabbit or mouse PAP; Sternberger-Meyer), diluted $1: 200$ in $2 \%$ NGS or $5 \%$ milk TBS.

For protocol $\mathrm{B}, 0.5 \mathrm{M}$ TBS $(0.9 \% \mathrm{NaCl})$ was used. Sections were pretreated $(30 \mathrm{~min})$ in $0.2 \% \mathrm{Tx}$-TBS at room temperature and incubated $(48 \mathrm{hr})$ in primary antibody diluted in $0.3 \%$ Tx-TBS $/ 1 \%$ NGS or $5 \%$ milk. Sections were rinsed in TBS and incubated (overnight) in secondary antibody diluted in $0.3 \% \mathrm{Tx}$-TBS/1\% NGS or $5 \%$ milk. After 


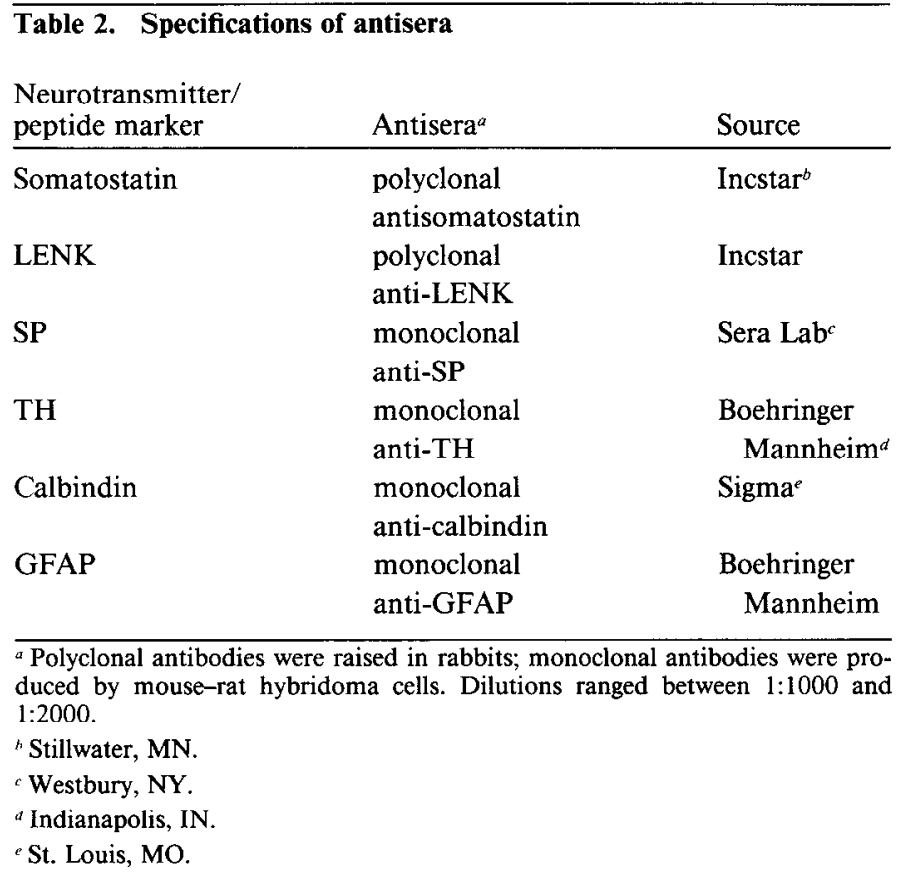

secondary antibody incubation, the sections were rinsed at room temperature and incubated in PAP diluted in $0.3 \%$ Tx-TBS/ $1 \%$ NGS or $5 \%$ milk.

For protocol C, the same buffer as in protocol B was used. Sections were pretreated ( $5 \mathrm{~min}$ ) with $10 \%$ methanol $/ 3 \% \mathrm{H}_{2} \mathrm{O}_{2}$, rinsed in TBS, and permeabilized $(30 \mathrm{~min})$ with $0.2 \% \mathrm{Tx}$-TBS at room temperature. Sections were incubated $(48 \mathrm{hr})$ in primary antibody diluted in $1 \%$ NGS or $5 \%$ milk/TBS. Sections were rinsed in TBS, incubated $(1 \mathrm{hr})$ in secondary antibody diluted in 1\% NGS or milk/TBS, rinsed in TBS, and incubated $(1 \mathrm{hr})$ in PAP diluted in $1 \%$ NGS or milk/TBS at room temperature.

For all protocols, following the PAP step, sections were rinsed, and peroxidase activity was visualized using a standard diaminobenzidine (Sigma) reaction. Slides were coded and evaluated without knowledge of the subjects' rearing history, although some SD monkeys showed macroscopic differences in staining intensity for some neurotransmitters.

Mapping and quantitation of immunoreactive neurons within the striatum and substantia nigra were achieved using a computerized, video-based plotting system that included a Dage 70 series video camera with a high-gain setting for low light levels, a Zeiss Axiophot microscope, Minnesota Datametrics digitizing stage encoders, an AT-compatible computer, an Imaging Technology FG100 digitizing and display board, and a Hewlett Packard 7475A plotter. The software was provided by Dr. M. Molliver (Department of Neuroscience, The Johns Hopkins University School of Medicine) and adapted by C. Fleischman (Neuropathology Laboratory, The Iohns Hopkins University School of Medicine). Operationally, the sections were scanned as the stage encoders record specimen position, with a resolution of $5 \mu \mathrm{m}$, and the video camera displayed constantly the field of view and captured a digital image of the field. Identifying symbols were placed over selected cells, using a mouse to control the cursor on the screen. The computer stored information on previously charted neurons and displayed cells on the screen when a region was rescanned. Similar procedures were used to draw boundaries of brain sections, outline contours of striatal patches, and trace fiber profiles in detail. After the section was mapped, the computer provided statistics on cell number and density and produced color-coded hard copies of the area of interest within the section of brain.

In age-matched SD and SR monkeys, we mapped sections of the striatum, prepared immunocytochemically for substance $P$ and somatostatin, at rostral, middle, and caudal levels. In addition, in agematched SD and SR monkeys, we counted the numbers of TH-immunoreactive neurons and the numbers of Nissl-stained perikarya in four sections (matched by level) through the ventral tegmental area (VTA) and substantia nigra pars compacta. Statistical analyses of data were performed using a Student's two-tailed $t$ test for independent or paired samples. Probabilities of $5 \%$ were interpreted as statistically significant.

\section{Results}

Histology

Grossly, the brains of SD and SR monkeys were indistinguishable. The histological appearance of the striatum, amygdala, and adjacent basal forebrain regions of SD monkeys was normal. In sections stained with cresyl violet or hematoxylin and eosin, there was no apparent evidence of neuronal cell loss, atrophy, or glial cell proliferation. Sections stained immunocytochemically for glial fibrillary acidic protein (GFAP) verified the lack of glial changes. In the striatum, large $(20-60 \mu \mathrm{m})$ neuronal cell bodies were intermingled with the prcponderant medium-sized (10-20 $\mu \mathrm{m})$ neuronal somata in apparently normal proportions. In the amygdala and bed nucleus of the stria terminalis, the major subdivisions were clearly discernible, and they showed no visually apparent cytoarchitectonic changes. In the absence of Golgi analyses, we cannot comment on dendritic morphology and orientation or axonal branching.

\section{Chemoarchitecture}

The different immunocytochemical protocols used for processing brain sections from SR and SD monkeys yielded differences in the intensities and details but not in general patterns or trends of changes in immunostaining between SD and SR monkeys. In these preparations, immunoreactivity was localized to perikarya and processes (dendrites, fibers, and putative terminals) of neurons. The results obtained using protocols A and B were similar with respect to patterns, but protocol $A$ was superior to protocol $\mathrm{B}$, because more authentic, immunoreactive neuronal perikarya were visualized using the former method, and because the numbers of peptide-containing cell bodies in the striatum and amygdala appear comparable to those in colchicine-treated monkeys. Protocol $\mathrm{C}$ was relatively insensitive compared to protocols $\mathrm{A}$ and $\mathrm{B}$. The poorer results of protocol $\mathrm{C}$ likely result from inadequate exposure of antigens due to less use of permeabilizing agents. Our descriptions are based primarily on sections processed using the most sensitive method (i.e., protocol A).

\section{Basal ganglia}

Socially reared monkeys. The topography of the striatum in normal adult rhesus monkeys has been defined based on differential patterns of immunoreactivity for TH, SP, enkephalin, somatostatin, and calbindin (Haber and Elde, 1982; Graybiel and Ragsdale, 1983; Martin et al., 1990; Hadfield et al., 1989; Cork et al., 1990). Patterns of immunoreactivity in the striatum of individual SR monkeys varied little among animals. As in previous studies (Haber and Elde, 1982; Graybiel and Ragsdale, 1983; Martin et al., 1990; Hadfield et al., 1989; Cork et al., 1990), the striatal mosaic was divisible into two distinct compartments - the patches (striosomes) and the matrix (see Figs. $1,2,4,5)$. In the caudate nucleus and putamen, the patches were enriched in immunoreactivity for SP and LENK, but immunoreactivity for TH was low. SP and LENK patches consisted of islands of immunoreactive neurons and processes (fibers and terminals). In contrast, the striatal matrix was more enriched in TH- and somatostatin-immunoreactive processes (fibers and terminals) and calbindin-immunoreactive neuronal perikarya than in the patches (Figs. 1-3); it contained SP and LENK 
immunoreactivity as well. Matrical regions of enriched TH immunoreactivity were associated with a feltwork of several fiber types and terminals and overlapped with regions highly immunoreactive for calbindin. Focal islands, less dense in $\mathrm{TH}$ and calbindin immunoreactivity than the matrical neuropil, occurred throughout the striatum. In the caudate nucleus, these islands low in TH immunoreactivity corresponded to the patches that were enriched in SP and LENK.

A different pattern was seen in the nucleus accumbens: regions showing little TH were in spatial register with focal regions low in SP and LENK. Regions with high levels of SP- and LENKimmunoreactive cell bodies, fibers, and terminals overlapped a matrix rich in TH. Somatostatin-immunoreactive fibers and terminals were more enriched in the nucleus accumbens than in the dorsal striatum. In addition, fewer neurons and less neuropil were immunoreactive for calbindin in the medial nucleus accumbens than in the matrix of the caudate nucleus.

The globus pallidus of SR monkeys showed its characteristic patterns of immunoreactivity. For example, peridendritic IENK immunoreactivity (woolly fibers) was enriched in the external pallidal segment but less dense in the internal pallidal segment. Peridendritic immunoreactivity for SP was sparse throughout external globus pallidus, except for the perimeter, and enriched in the internal globus pallidus.

Socially deprived monkeys. The striatal chemoarchitecture in the behaviorally impaired SD monkeys differed greatly from the patterns in SR monkeys. Sections from the four totally SD monkeys showed consistent changes in the patterns of immunoreactivity within the striatum (Figs. 1, 2, 4-6). Similar trends were observed in male and female SD monkeys.

The caudate nucleus, putamen, and nucleus accumbens of the SD monkeys were all affected, but all regions were not equally affected. Of the striatal regions, the nucleus accumbens was least affected, and the caudate nucleus and putamen were most affected. In SD monkeys, neuropeptide immunoreactivity was severely changed in the head, body, and tail of the caudate nucleus and in the putamen. The normally well-defined patches containing SP- and LENK-immunoreactive neurons and terminals were greatly diminished in the caudate and putamen (Figs. 1, 4-6), and there were also decreases in SP- and LENKimmunoreactive neurons and terminals in the matrix. The average density of SP-immunoreactive neuronal cell bodies within the striatum was reduced $58 \%$ in SD monkeys (Table 3). Terminal immunoreactivity for SP and LENK was reduced only slightly in the nucleus accumbens of SD monkeys. In an attempt to enhance immunoreactivity for SP and LENK, additional sections were placed in the chromogen for longer periods, but this did not enhance specific staining in the SD subjects and instead resulted in an increase in nonspecific background staining when compared to control sera.

The density of TH-immunoreactive fibers and axonal terminals within the matrix of the caudate nucleus and putamen in SD monkeys was reduced compared to controls, and in serially adjacent sections there was a corresponding reduction in calbindin immunoreactivity (Figs. 1, 2, 6). TH immunoreactivity in the nucleus accumbens was also diminished in SD monkeys but to a lesser degree.

In contrast to the changes in SP, LENK, TH, and calbindin immunoreactivity, patterns of somatostatin immunoreactivity were unchanged in the striatum. Somatostatin-immunoreactive processes were enriched in the striatum, and neuronal cell bodies immunoreactive for somatostatin showed their characteristic distribution (Figs. 3, 4). The average density of somatostatinimmunoreactive neurons within the striatum of SD and SR monkeys did not differ significantly, although there was a trend for SD monkeys to have more neurons and a greater variance in average neuronal density (Table 3 ).

Three additional observations support our data on changes in the striatal chemoarchitecture of SD monkeys. First, corresponding losses in terminal reactivity for SP and LENK were observed in the globus pallidus and substantia nigra (Figs. 5, 6); targets of projections from medium-sized spiny striatal neurons, but the ventral pallidum did not appear significantly affected. Second, SP immunoreactivity was reduced in thalamic nuclei related to the basal ganglia (Fig. 5). Third, the average number of TH-immunoreactive neuronal cell bodies in the substantia nigra pars compacta and VTA, the source of dopaminergic input to the striatum, was reduced significantly $(43 \%)$ in three SD monkcys $($ mcan $=624$ ncurons/section; standard deviation 231 neurons) relative to three SR monkeys (mean $=1087$ neurons/section; standard deviation $=167$ neurons). VTA and compacta neurons both seemed to be affected; however, further quantitative analyses are needed to establish if the substantia nigra compacta is more affected than the VTA. In contrast, neuronal counts in the substantia nigra pars compacta/VTA, based on cresyl violet-stained sections, did not differ significantly between the two groups, suggesting that nigral neurons in SD monkeys have a reduced capacity to produce $\mathrm{TH}$.

\section{Amygdala and basal forebrain}

Of the subcortical structures surveyed in this study, the decreases in immunoreactivity for TH, SP, LENK, and calbindin in the striatum and associated regions of the basal ganglia in SD monkeys appeared regionally specific. In the same sections, the patterns of immunorcactivity for thcse markers appeared unchanged in adjacent subcortical forebrain regions (Figs. 7, 8). Patterns of immunostaining for TH, SP, LENK, and calbindin appeared normal in the nuclear divisions of the amygdala, defined broadly as the lateral, basolateral, basomedial, cortical, medial, and central nuclei. In SD and SR monkeys, TH immunoreactivity (fibers and terminals) was discretely distributed in moderate to high densities in the lateral, basolateral, and central nuclei, and less labeling was localized in the cortical and medial nuclei. The central nucleus was enriched in LENK and somatostatin immunoreactivity in SD and SR monkeys (Fig. 7). The capsular and medial part of the central nucleus displayed somatostatin and LENK immunoreactivity in the form of fine, varicose fibers, puncta, and peridendritic and perisomatic profiles. Neuronal perikarya immunoreactive for LENK and somatostatin were localized in the central part of the central lateral division. In the medial nucleus of the amygdala, processes and neurons immunoreactive for SP or calbindin were abundant irrespective of rearing condition.

Recent studies of the cyto- and chemoarchitecture of the basal forebrain of primates indicate that the bed nucleus of the stria terminalis (BST) is continuous through the substantia innominata with parts of the central and medial nuclei of the amygdala (Martin et al., 1988; de Olmos, 1990). In the BST-amygdala continuum of SD monkeys, patterns of immunoreactivity appeared unchanged (Fig. 8). Somatostatin- and LENK-immunoreactive neurons were present in their normal distributions within the central part of the lateral division of the BST. This division was also innervated densely by $\mathrm{TH}$-immunoreactive terminals. Parts of the lateral BST, particularly the capsular, 

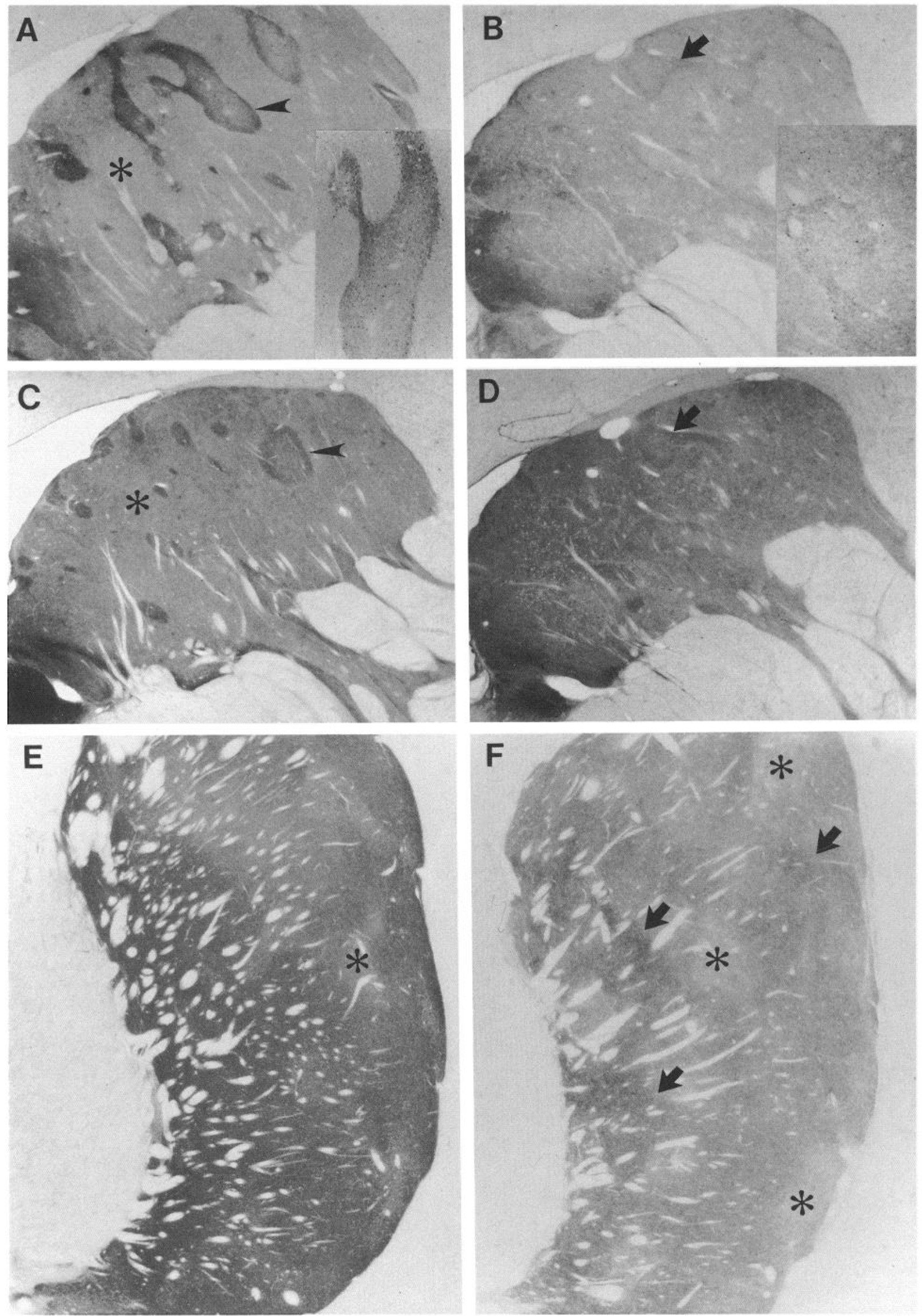

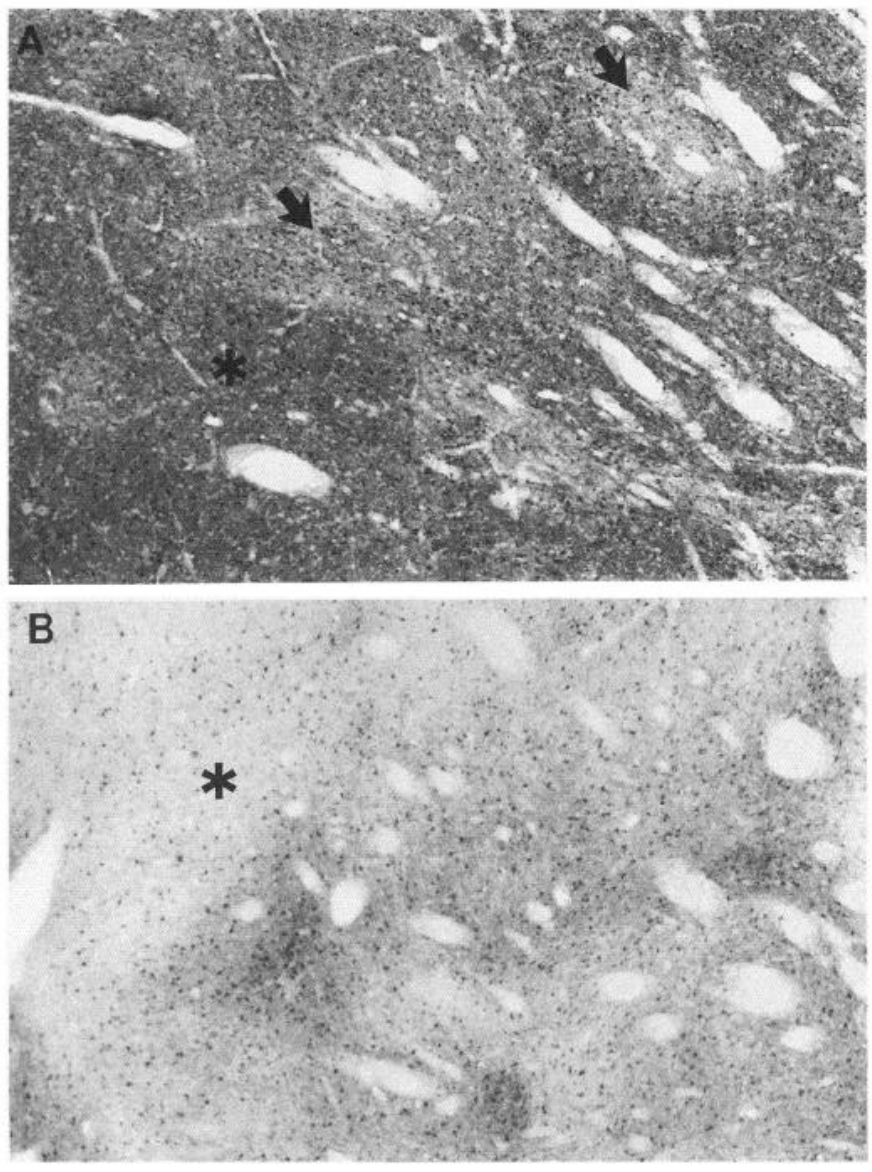

Figure 2. Calbindin immunoreactivity in the putamen of SR control monkeys $(A)$ and SD monkeys $(B)$. In control monkeys $(A)$, the matrix (asterisk) contained many intensely immunoreactive neurons. Patches (arrows) had less immunoreactivity for calbindin than the matrix. In SD monkeys $(B)$, calbindin immunoreactivity was greatly reduced in the putaminal matrix (asterisk). Magnification, $400 \times$.

posterior, and ventral parts, were enriched in peridendritic and perisomatic immunoreactivity for somatostatin and LENK. The medial division of the BST was enriched in SP immunoreactivity. Within the sublenticular substantia innominata, a dense, well-delineated plexus of somatostatin- and LENK-immunoreactive woolly fibers extended from the ventral BST to the dorsal part of the central amygdalar nucleus in all monkeys regardless of rearing history (Fig. 8).

The basal forebrain magnocellular complex also appeared unaffected in SD monkeys. Acrolein fixation is incompatible with available cholinergic markers (e.g., ChAT immunocytochemistry or AChE histochemistry) for the magnocellular complex. Thus, we relied on Nissl- and calbindin-stained sections, be-
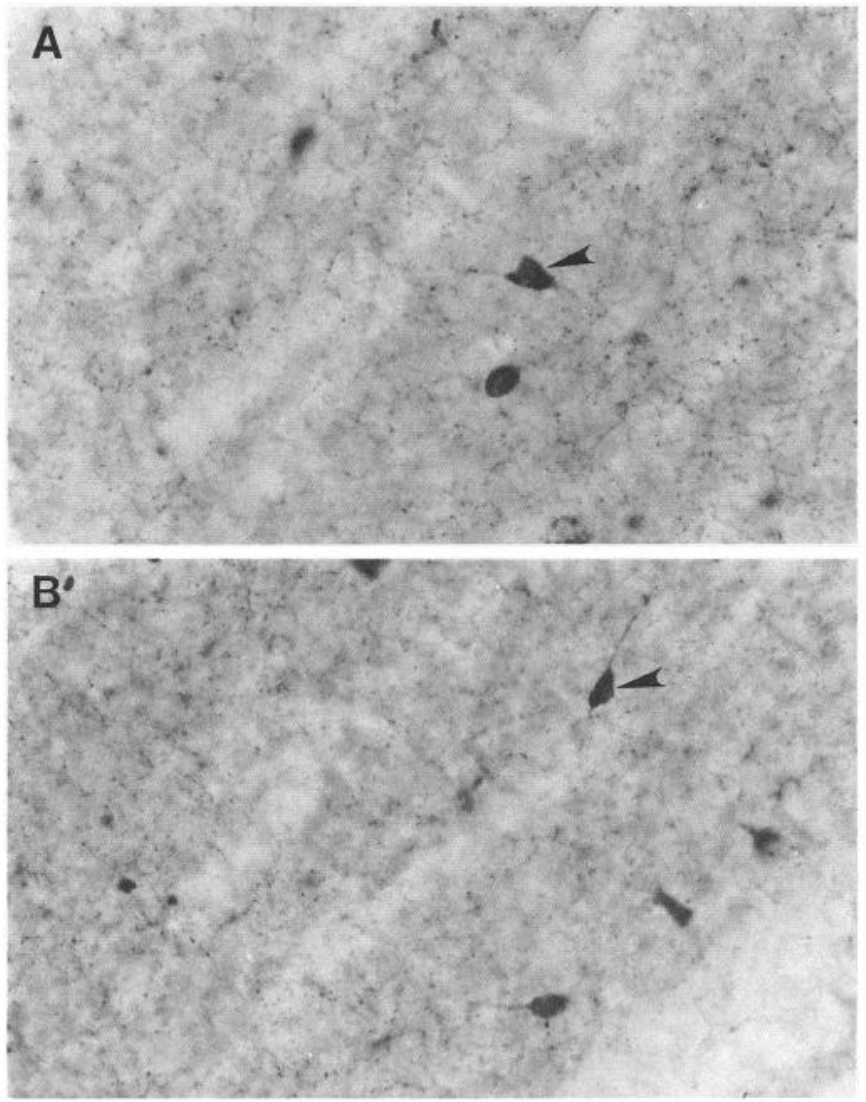

Figure 3. Patterns of somatostatin immunoreactivity in the striatum of SR $(A)$ and $\mathrm{SD}(B)$ monkeys did not appear to differ. Both groups of monkeys had the normal distributions of somatostatin-immunoreactive neuronal cell bodies (arrowheads) and processes. Magnification, $400 \times$.

cause calbindin and ChAT colocalize in neurons of the cholinergic basal forebrain complex in primates (Celio and Norman, 1985; Schatz et al., 1990). In SD monkeys, we did not see qualitative differences in the distribution, density, or size of neurons in the basal forebrain magnocellular complex.

\section{Discussion}

This study demonstrates that nonhuman primates that experienced abnormal environmental conditions, that is, social/sensory deprivation, during the first year of life have pronounced alterations in the patterned arrangements and organization of neurotransmitters in the basal ganglia. The caudate nucleus, putamen, and substantia nigra appear to be more vulnerable to social/sensory deprivation than the nucleus accumbens, amygdala, BST, substantia innominata, and basal forebrain magno-

Figure 1. Differences in striatal compartmentalization of SP, LENK, and TH in SR and SD monkeys. The striatum in SR monkeys was intensely immunoreactive for SP $(A)$, LENK $(C)$, and TH $(E)$. Patterns of immunoreactivity for SP and LENK were similar. In the caudate nucleus, SP $(A)$ and LENK $(C)$ immunoreactivity was patchy (arrowheads) and associated with clusters of neuronal cell bodies and fine fibers and puncta (inset in $A$ ). The matrix (asterisks) had more loosely distributed SP and LENK neurons and less puncta than the patches. Immunoreactivity for TH in SR monkeys was very dense in the matrix of the putamen $(E)$. Throughout the striatum, the patches were less dense in TH-immunoreactive fibers and terminals than in the matrix (asterisk). In the SD monkeys immunoreactivity for SP $(B)$, LENK $(D)$, and TH $(F)$ was diminished, and the mosaic ordering was less prominent than in controls. Photographs in $B$ and $D$ are from adjacent sections. In the caudate nucleus, well-defined patches of neurons and processes immunoreactive for SP $(B)$ and LENK $(D)$ were visualized infrequently, and the remaining patches (arrows) showed lighter immunoreactivity (inset in $B$ ). In the matrix, neuronal cell bodies and processes immunoreactive for SP and LENK were also affected. In the putamen of SD monkeys $(F)$, TH-immunoreactive fibers and terminals were depleted markedly in the matrix (arrows) but less severely affected in the patches (asterisks). Magnification, $25 \times$. 
A

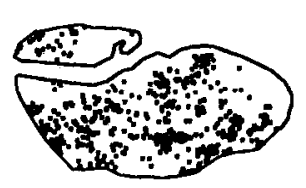

B
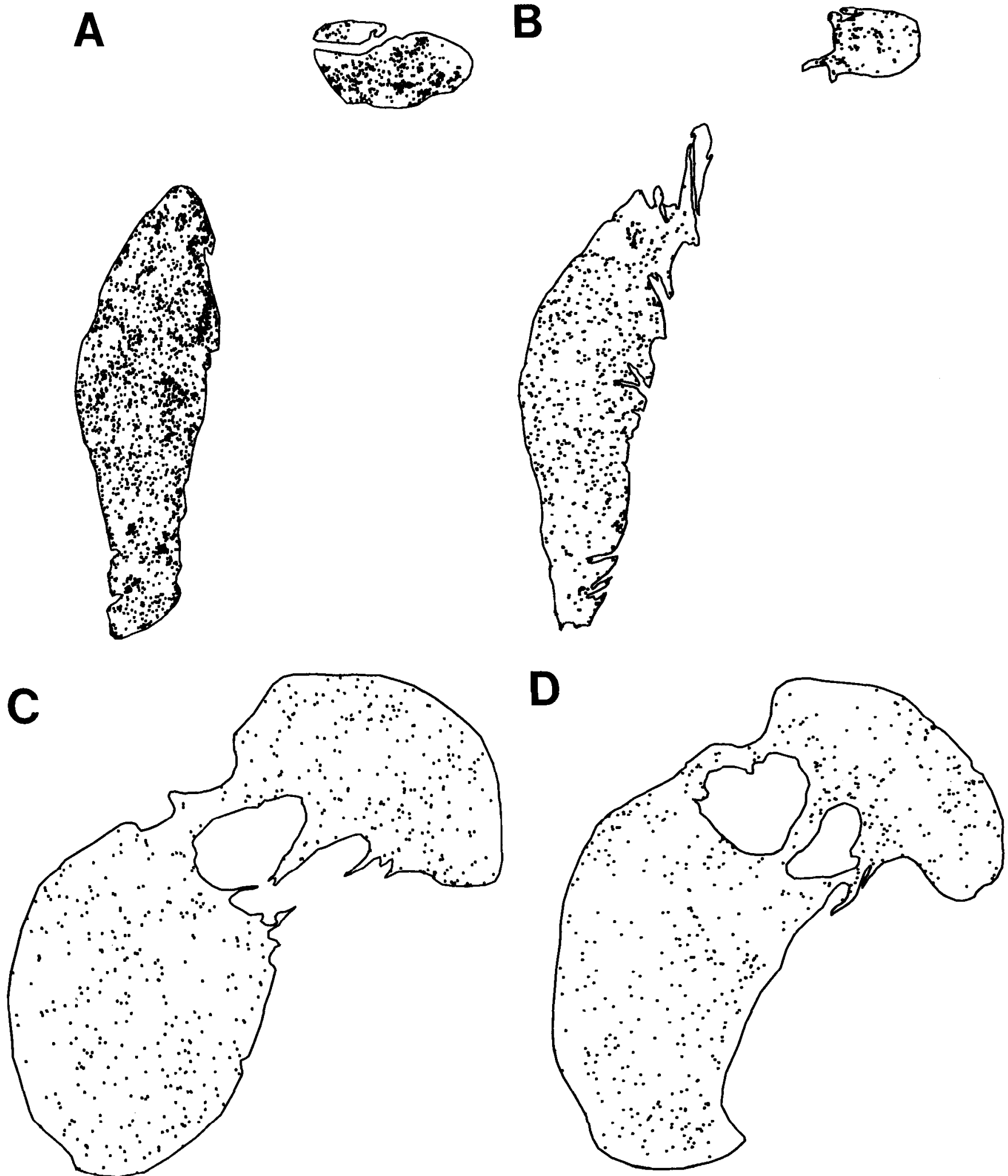

Figure 4. Representative maps showing the distributions of neuronal cell bodies immunoreactive for SP $(A$ and $B)$ and somatostatin $(C$ and $D)$ in middle- or caudal-level sections through the striatum of SR and SD monkeys. Each dot represents one neuron. SP-immunoreactive neurons within patch and matrix compartments were depleted markedly in SD monkeys $(B)$ relative to SR controls $(A)$. Note the loss of clusters (patches) of SP-immunoreactive neurons in the SD monkey. Approximately 1,000 to 3,000 neurons per section were counted, depending on the level of section. The distribution and density of somatostatin-immunoreactive neurons were not changed within the striatum of SD monkeys $(D)$ compared to SR monkeys $(C)$. 

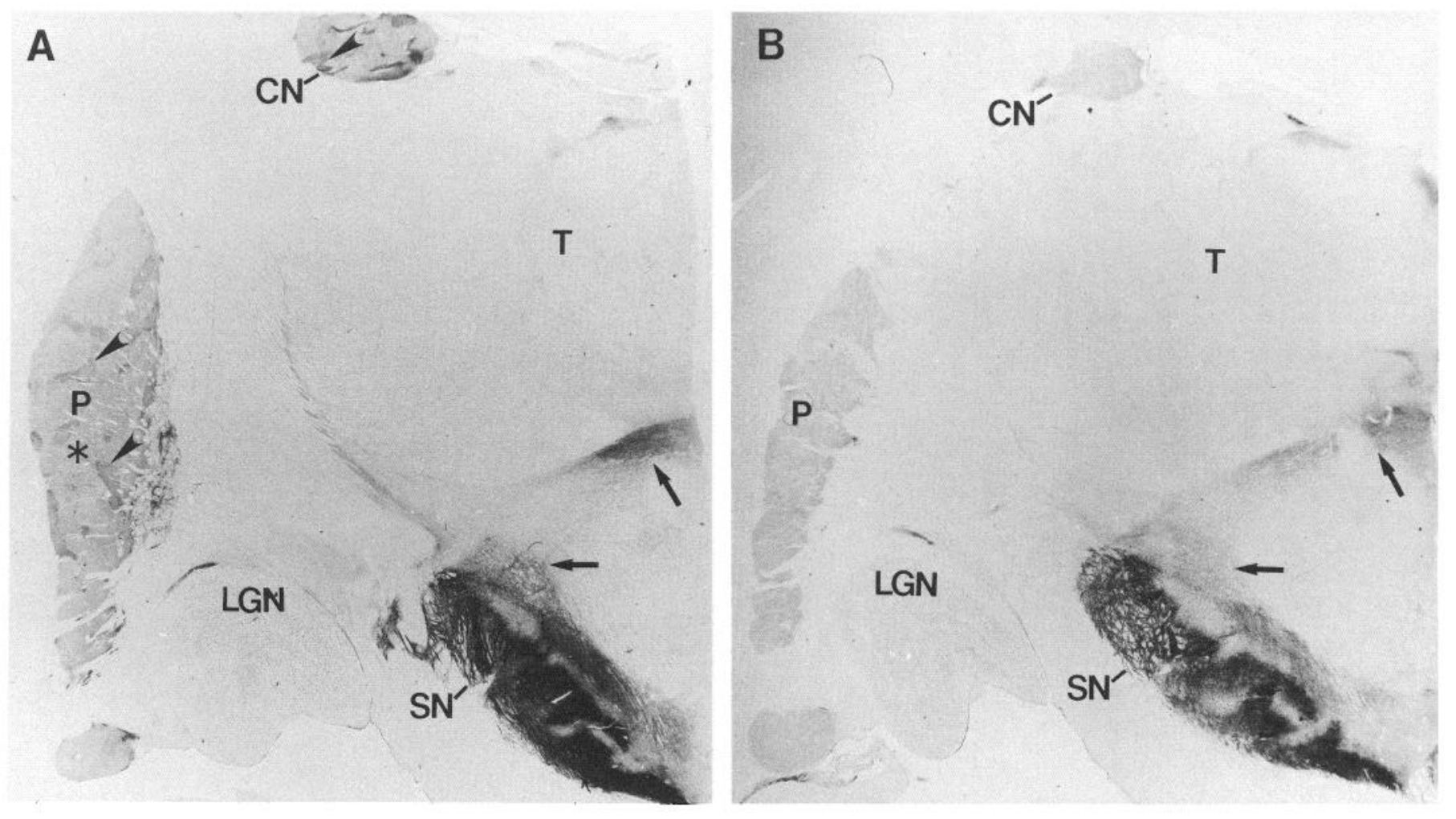

Figure 5. SP immunoreactivity in the basal ganglia of control, SR monkeys $(A)$ and SD monkeys $(B)$. Several regions in $A$ were enriched in SP immunoreactivity, including the body and tail of the caudate nucleus $(C N)$, putamen $(P)$, and substantia nigra $(S N)$. Note the SP-enriched patches $(A$, arrowheads) and the moderately stained matrix (asterisk) in the caudate nucleus and putamen of the SR monkey. The SN is also enriched in $\mathrm{SP}$ immunoreactivity in the control monkeys as well as the region in the vicinity of the basal ventral medial nucleus of the thalamus (arrows). In the SD monkeys, there was a loss of SP patches, the matrix was more lightly stained, and terminal immunoreactivity in the SN and thalamus $(T)$ was reduced. $L G N$, lateral geniculate nucleus. Magnification, $5.5 \times$.

cellular complex. Moreover, our observations suggest that the organization of chemically distinct compartments within the striatum of primates is not immutable and that the normal postnatal maturation of the striatum may be in part environmentally determined. Social and sensory deprivation in infancy may produce permanent structural and neurochemical changes in some subcortical basal ganglia regions mechanistically similar to induced changes in the development of visual and somatosensory systems.

In SD monkeys, the striatal matrix was severely affected as demonstrated by the loss of calbindin and TH immunoreactivity. This observation was complemented by a decrease in THimmunoreactive neurons in midbrain dopaminergic groups that project to striatum. Both patch and matrix compartments normally enriched in SP or LENK were also depleted in SD monkeys. The finding that medium spiny projection neurons of the striatum are affected is further supported by the loss of SP and LENK immunoreactivity in their targets (e.g., globus pallidus and substantia nigra pars reticulata). Together, these observations might reflect a general decrease in striatal function. However, patterns of somatostatin immunoreactivity in SD and SR monkeys did not differ significantly, indicating a selective decrease for some striatal neurotransmitters. Thus, it is difficult to conclude that an overall decrease in striatal function accounts for these observations in SD monkeys, nor is it possible to conclude that there was a generalized decrease in immunoreactivity for LENK, SP, calbindin, or TH, since other brain regions (e.g., bed nucleus of the stria terminalis, amygdala, nucleus basa- lis of Meynert) in the same section and adjacent to the striatum did not show changes in these neurotransmitter markers.

\section{Methodological considerations}

Although fixation and processing protocols are important variables in immunocytochemical studies, the changes we observed are unlikely to be the result of technical variables. The advantages of acrolein fixation for subsequent visualization of neuropeptide immunoreactivity in cell bodies and processes have been described previously (King et al., 1983), and we have previously employed this fixative, with excellent results, for delineation of striatal patch and matrix compartments (Martin et al., 1990; Hadfield et al., 1989; Cork et al., 1990) as well as for other forebrain regions (Martin et al., 1988). Moreover, brain

\begin{tabular}{|c|c|c|}
\hline & SP & Somatostatin \\
\hline SR & $50.8 \pm 12.9$ & $7.7 \pm 1.0$ \\
\hline SD & $21.2 \pm 4.3^{*}$ & $9.8 \pm 2.7$ \\
\hline
\end{tabular}

See Materials and Methods for details on cell counting. Values are mean \pm standard deviation. Sections at representative rostral, middle, and caudal levels of the striatum were mapped. For SP, three SR and two SD monkeys were used. For somatostatin, three SR and four SD monkeys were used.

* Significantly different $(p<0.05)$ from control. 

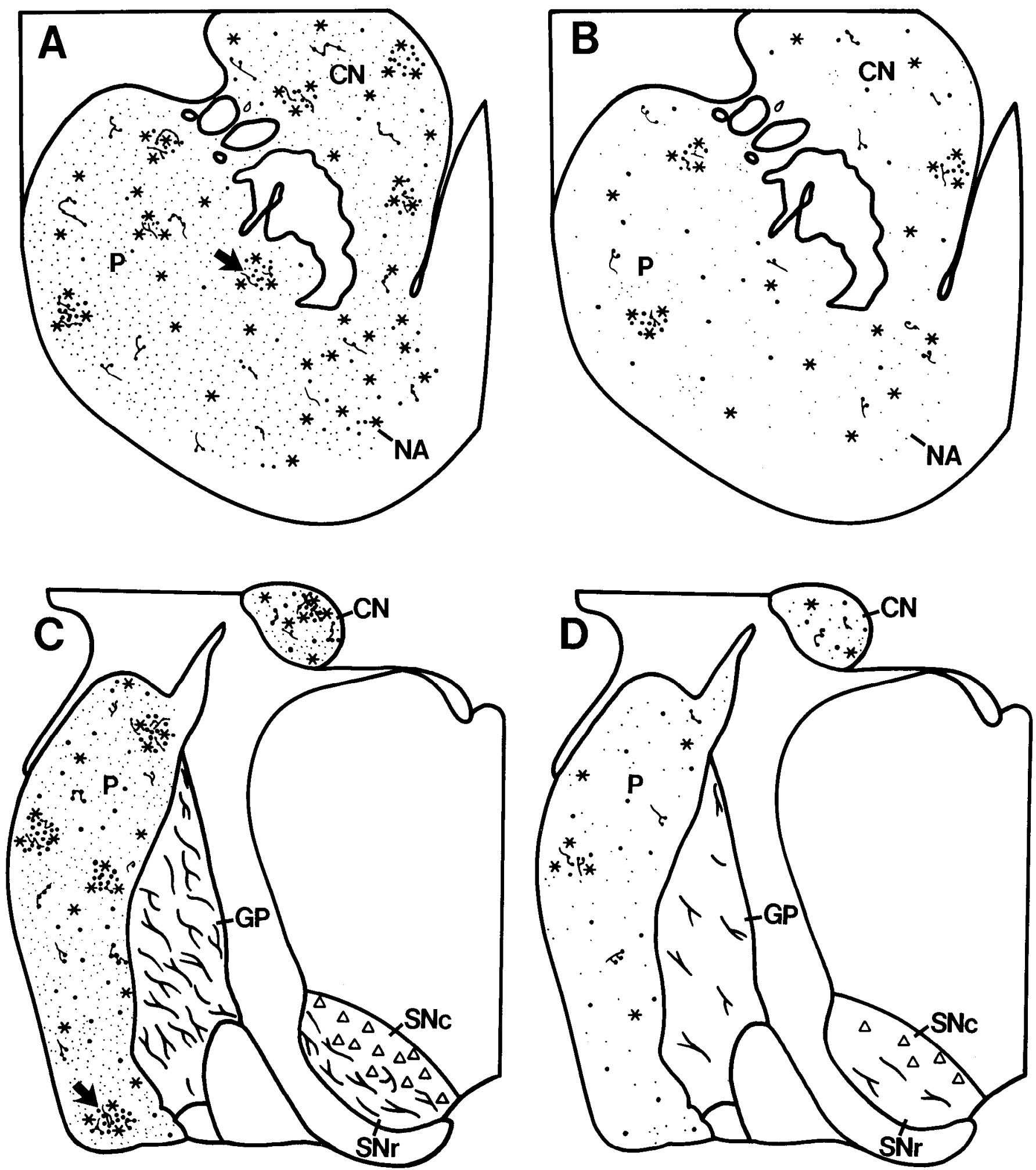

Figure 6. This diagram depicts some of the features of the organization of the primate striatum and its inputs and outputs in SR and SD monkeys. $A$, SR monkeys: SP-immunoreactive neurons (asterisks), fibers (short, beaded lines), and terminals (solid circles) were enriched in some areas to form discrete patches (arrows) but also were distributed diffusely throughout the matrix of the caudate nucleus $(C N)$ and putamen $(P)$. The putamen contained fewer patches than the caudate. Patches also contained LENK immunoreactivity in a distribution that was similar to SP. The nucleus accumbens $(N A)$ had a matrix enriched in SP and LENK immunoreactivity. TH-immunoreactive terminals (small dots) formed a diffuse matrix throughout the caudate, putamen, and nucleus accumbens, but there was less immunoreactivity in the patches. Calbindin-immunoreactive neurons (not shown) were similar in distribution to that of TH terminals. Somatostatin immunoreactivity (not shown) was present in both patch and matrix compartments, but processes were relatively enriched in the matrix. $B, \mathrm{SD}$ monkeys: patch and matrix regions as delineated by SP neurons, fibers, and terminals were decreased compared to controls; TH terminals were decreased in the matrix. LENK was also decreased in the patches and matrix. Calbindin was decreased in matrix, and somatostatin was unchanged. $C$, SR monkeys: patterns of immunoreactivity in the caudate and putamen were similar to those seen in Figure $6 \mathrm{~A}$. SP-and LENK-immunoreactive terminals, forming peridendritic arrays (smooth, branching lines), 
tissues from SD and SR monkeys were prepared identically, and sections were processed simultaneously using the same reagents. It is also unlikely that the changes in the striatal neurochemical architecture of SD monkeys are the result of aging. We have studied the brains of aged monkeys using immunocytochemical techniques similar to those used here, but we have not observed alterations in the striatum comparable to those changes seen in the SD monkeys (Kitt et al., 1984, 1985; Struble et al., 1984).

\section{Possible mechanisms accounting for chemoarchitectonic changes in SD monkeys}

We do not know why the basal ganglia appear to be more vulnerable to the effects of early social deprivation than other brain regions that we have studied. Several mechanisms could explain these observations, including alterations in individual activity or changes in behavioral state (e.g., stress), abnormalities in afferent regulation of target regions, or perturbations in postnatal development.

It is possible that the changes in the basal ganglia may reflect a behavioral state- or activity-dependent phenomenon; that is, the ongoing behavioral state of these animals at the time of death could be a mechanism producing changes in striatal chemoarchitecture. The concentration of SP immunoreactivity in monkey visual cortex (Hendry et al., 1988) and the level of preproenkephalin mRNA in the nucleus of the spinal tract of the trigeminal nerve (Nishimori et al., 1990) show an activitydependent regulation. This seems an unlikely explanation, because the general physical activity of SD monkeys initially is equal to or greater than that of SR controls (Griffin and Harlow, 1966; Miller et al., 1971; Fittinghoff et al., 1974); thus, the quality and nature of the motoric activity, rather than the frequency of the activity, may be an important variable. Furthermore, these changes may result from early, chronic stress. At 2 $\mathrm{yr}$ of age, these SD monkeys had consistently higher basal levels of plasma cortisol than SR subjects, but they did not have a higher rise in plasma cortisol than controls following adrenocorticotropic hormone injection or playroom stress (Sackett, 1972a). Stress can produce neuropathological changes in hippocampus (Uno et al., 1989), but effects of stress on the basal ganglia in early postnatal periods are not clear.

Another explanation is that striatal afferents have important roles in the steady-state regulation of peptide expression in medium spiny neurons in adult animals. Medium spiny neurons containing SP or enkephalin receive synaptic input from dopaminergic nigrostriatal and excitatory corticostriatal afferents (Kubota et al., 1986a,b; Gerfen, 1988). Treatment of rats with dopamine antagonists, and manipulation of dopaminergic projections to the striatum, can influence levels of striatal peptides and mRNA transcripts encoding for peptides. Specifically, haloperidol treatment decreases SP immunoreactivity, SP mRNA, and preprotachykinin mRNA but increases enkephalin immunoreactivity in the striatum (Hong et al., 1979; Bannon et al., 1986). Similarly, destruction of the nigrostriatal dopaminergic system decreases cellular levels of mRNA encoding for SP but
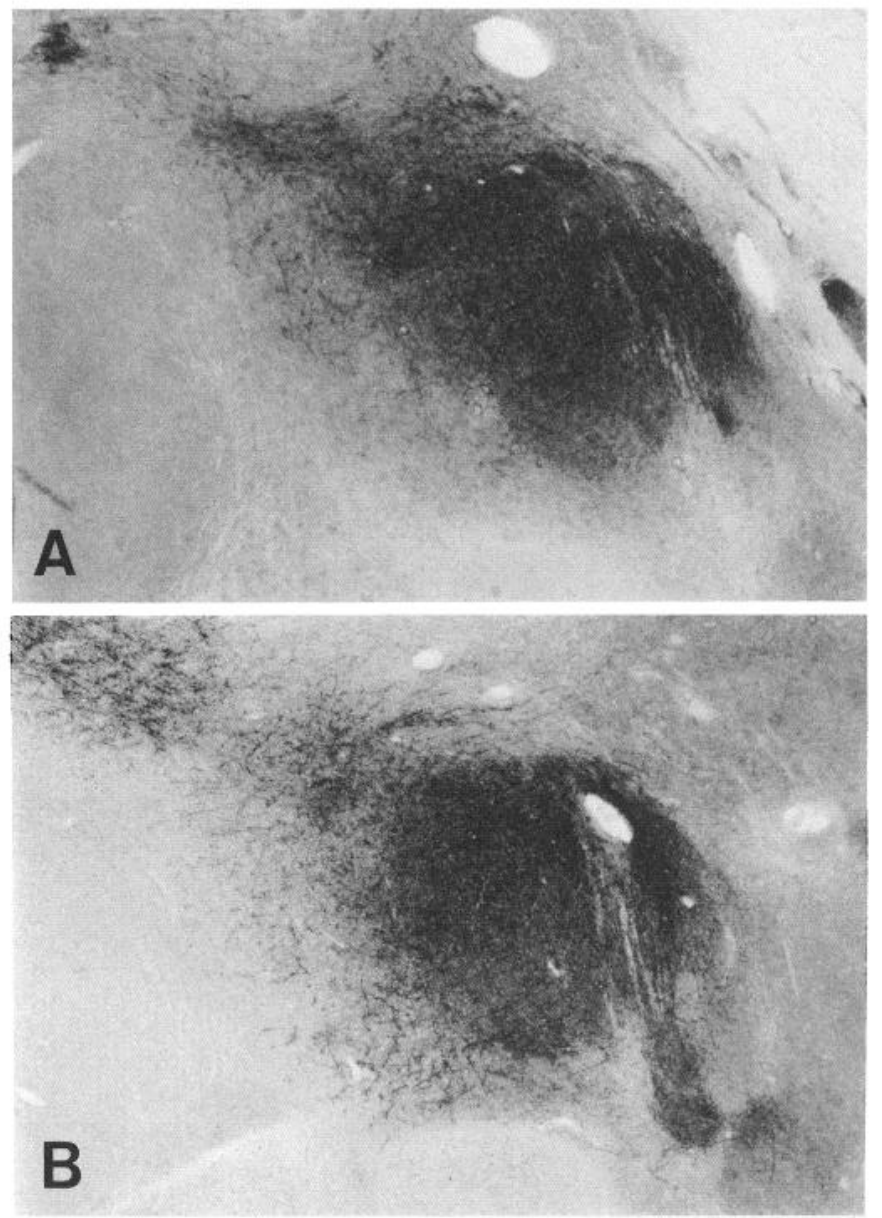

Figure 7. Patterns of LENK immunoreactivity in the central amygdalar nucleus in SD $(A)$ and SR $(B)$ monkeys. In SD and SR monkeys, the central nucleus of the amygdala was enriched in LENK-immunoreactive neuronal perikarya, woolly fibers, and putative terminals. The central nucleus of the amygdala also showed similar patterns of immunoreactivity for somatostatin in SD and SR monkeys. Magnification, $50 \times$.

increases cellular levels of mRNA encoding for enkephalin (Young et al., 1986). In addition, $\mu$-opiate receptors, localized in the patches on elements postsynaptic to dopaminergic terminals (Unterwald et al., 1989), disappear in the striatum following lesions of the nigrostriatal dopaminergic pathway (Sirinathsinghji and Dunnett, 1989).

Our observations showing changes in neuropeptides in the striatum of SD monkeys are only partially consistent with a dopaminergic denervation of the striatum. The loss of SP immunoreactivity, the reduction in the number of TH-immunoreactive neurons in the substantia nigra, and the dopamine receptor supersensitivity (Lewis et al., 1990) in SD monkeys would support this concept. However, nigral lesions in rats increase preproenkephalin mRNA and enkephalin immunoreactivity within the striatum (Young et al., 1986; Voorn et al., 1987). In

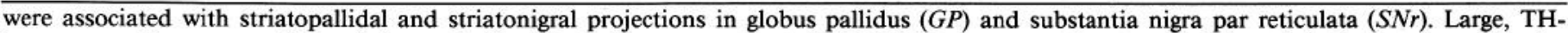

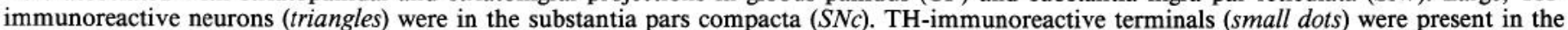

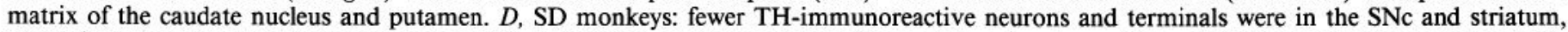

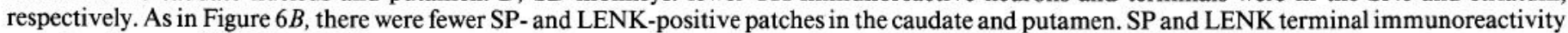
was also decreased in GP and $\mathrm{SNr}$. 


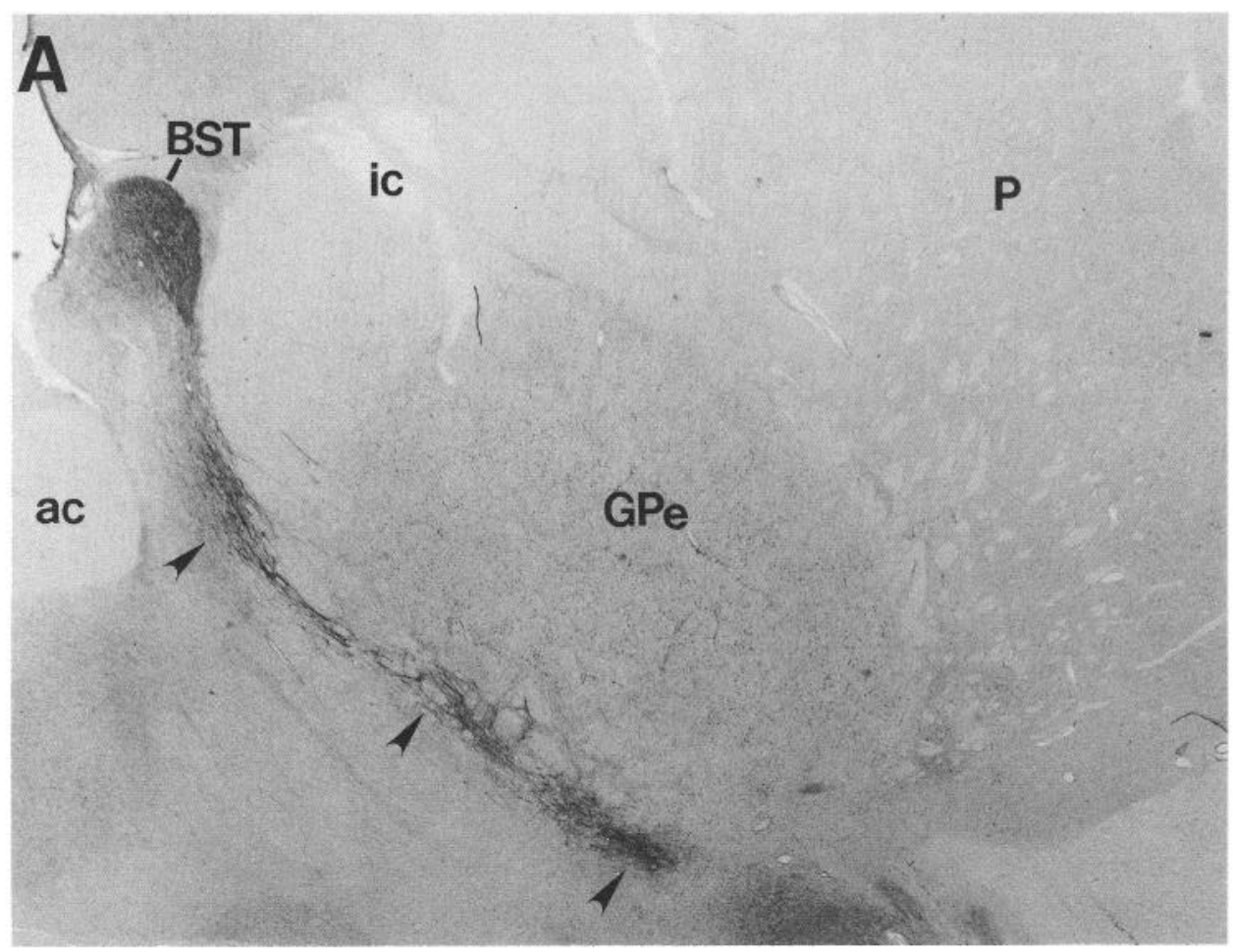

Figure 8. In SD $(A)$ and SR $(B)$ monkeys, patterns of immunoreactivity for somatostatin in the bed nucleus of the stria terminalis (BST) did not differ. Regardless of rearing history, the bed nucleus was enriched in perikaryal, punctate, and peridendritic immunoreactivity for somatostatin. The ventral continuation of the BST (arrowheads) into the substantia innominata was also unaffected in SD and SR monkeys. A similar pattern was seen with antisera to LENK. $P$, putamen. $G P e$, globus palliclus pars externa; $i c$, internal capsule; $a c$, anterior commissure. Magnification, $6.5 \times$.

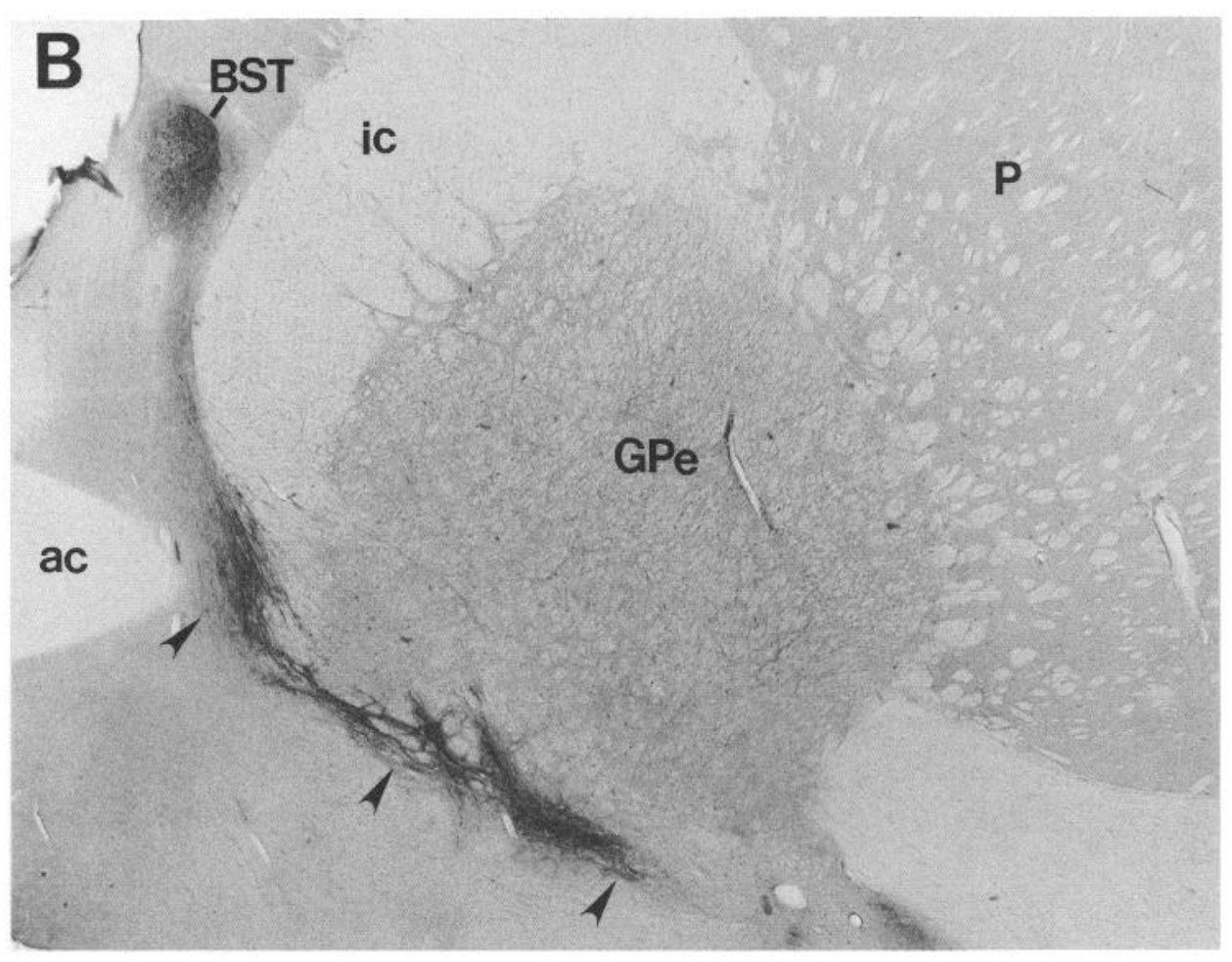

contrast, ablation of corticostriatal afferents reduces both preprotachykinin and preproenkephalin mRNAs in neurons of the striatum (Uhl et al., 1988; Somers and Beckstead, 1990). Striatal changes produced by cortical lesions may be mediated by reduced excitatory amino acid neurotransmission, thereby influencing steady-state levels of neuropeptides in striatal neurons (Somers and Beckstead, 1990). It is possible that changes within midbrain dopaminergic groups and within cerebral cortex and its glutamatergic projections are related to the alterations observed in the striatum of SD monkeys.
Alternatively, the postnatal development of basal ganglia chemoarchitecture may be vulnerable in SD infant monkeys. Striatal neurotransmitters and their receptors undergo remodeling during early postnatal periods to establish their final adult patterns. Ontogenetic changes in patch/matrix compartments are observed with monoamines, SP, enkephalin, and receptors for these transmitters as well as other neuropeptides and $\mathrm{ACh}$ (Liozou, 1972; Olson et al., 1972; Tennyson et al., 1972; Graybiel et al., 1981; Quirion and Dam, 1986; Lowenstein et al., 1989; Nastuk and Graybiel, 1989; Tribollet et al., 1989). In addition, 
pre- and postnatal changes in glycoconjugated molecules, neuropeptides, glutamate, and dopamine suggest that these substances may act as morphogenic growth regulators in the developing brain or as trophic factors for regional postnatal remodeling (Quirion and Dam, 1986; Lankford et al., 1988; Steindler et al., 1988; Tribollet et al., 1989; Bettler et al., 1990; Boylan et al., 1990). For example, early postnatal development of the mouse neostriatal mosaic involves cordoning off territories with galactosyl-containing glycoconguates synthesized by glial cells (Steindler et al., 1988). In cats, SP in medium spiny striatal neurons may function as a trophic factor before synaptogenesis in the neostriatum (Boylan et al., 1990). In rats, endogenous opiates can influence neuronal ontogeny by changing the time course and magnitude of dendritic arborization and spine elaboration (Hauser et al., 1987). The role of glutamate in synaptic plasticity is well recognized, and glutamate receptor gene transcripts are expressed in forebrain regions later in development and in regions where neuronal differentiation and synaptic formation may occur (Bettler et al., 1990). Interestingly, glutamate receptors are involved in experience-dependent, postnatal development of visual cortex (Kleinschmidt et al., 1987). Finally, dopamine or dopamine neurotransmission may play a role in neuronal morphogenesis during ontogeny. Depletion of dopamine retards synaptogenesis in the putamen of fetal rabbits (Tennyson et al., 1982), and presynaptic dopaminc may bc important for development of medium spiny neurons in the neostriatum (Tennyson et al., 1983). The normal development of enkephalinergic and SPergic systems in the basal ganglia is dependent on the availability of dopamine and/or the integrity of nigrostriatal dopamine neurons (Sivam and Krause, 1990), a view consistent with our observations in SD monkeys.

The pharmacological and physiological properties of nigrostriatal dopamine neurons indicate that they are in a dynamic state of flux during early postnatal development (Pitts et al., 1990). Postsynaptic synaptogenesis of terminals of nigrostriatal dopaminergic neurons is thought to continue postnatally in the striatum (Loizou, 1972; Olson et al., 1972). Moreover, in neonatal rats, dopamine $\mathrm{D}_{1}$-receptors are more dense in the striatum than in adjacent regions and are located preferentially in striatal patches (Lankford et al., 1988). In vitro, dopamine can reduce motility of growth concs of retinal neurons via $D_{1}$-receptor activation (Lankford et al., 1988) and stimulate retraction of photoreceptors via $\mathrm{D}_{2}$-receptor activation (Dearry and Burnside, 1986). A signal that retards motility of growth cones could facilitate adhesive contacts between filopodia and synaptic formation by stabilizing the cell-cell contacts of nascent junctions (Lankford et al., 1988). Because the regulation of striatal development by interactions of transmitler-specific neuronal systems is clearly complex, and because it may require a fine balance between a variety of factors or signals, postnatal pattern formation within the striatum may be particularly vulnerable to environmental factors. Early, postnatal social and somatosensory deprivation may interfere, directly or indirectly, with expression of specific molecules critical for formation and stabilization of neurochemically distinct compartments of the striatum in infant primates.

\section{The amygdala in SD monkeys}

It is intriguing that the chemoarchitecture of the amygdala is apparently unchanged in SD monkeys, because the amygdala in rhesus monkeys also matures postnatally as evidenced by the distribution of opiate receptors in newborn monkeys (Bachevalier et al., 1986). The behaviors of SD monkeys share many similarities with behaviors of monkeys with limbic lesions (MacLean, 1990) or monkeys that as infants received limbic lesions, that is, bilateral amygdalectomy and hippocampectomy (Bachevalier, 1990). Monkeys with limbic lesions are passive, withdraw from social contact, fail to play, and have locomotor stereotypies. However, bilateral amygdalectomy of newborn primates does not influence subsequent development of behaviors characteristic of SD monkeys (Kling and Green, 1967). These authors concluded that these behaviors are mediated by subcortical regions other than the amygdala (Kling and Green, 1967). Our chemoarchitectonic observations on SD monkeys are consistent with this supposition, and they suggest that abnormalities of the basal ganglia, but not the amygdala, may contribute to the behaviors of SD monkeys, perhaps because connections and neurotransmitters of the striatum mature more slowly than those of the amygdala. For example, corticostriate projections from prefrontal cortex in rhesus monkeys undergo postnatal maturational changes up to 24 months of age (Johnson et al., 1976). Thus, social deprivation for the first 9 months of life may interfere with the postnatal developmental timing of the striatum but not the amygdala.

\section{Complex neural circuits in SD monkeys}

Reductions in informative sensory input at critical stages of development produce many behavioral abnormalities (e.g., social inadequacies and self-directed or stereotyped behavior; see Table 1). Therefore, it is unlikely that changes in a single brain region are responsible for these alterations. Our data strongly suggest that social deprivation alters the normal development of patch and matrix compartments within the striatum. Multiple topographic, parallel, and functionally segregaled connections link cerebral cortex and striatum (Goldman and Nauta, 1977; Alexander et al., 1986; Gerfen, 1990). Electroencephalographic studies of other SD monkeys have shown that the most severely behaviorally impaired SD monkeys have physiologic aberrations in the caudate nucleus and sensory relay nuclei for proprioceptive and vestibular function in the cerebellum and somatosensory thalamus (Heath, 1972). A lack of tactile contact with other monkeys has been shown to be responsible for some of thesc bchaviors of SD monkcys (Missakian, 1969; Suomi, 1982). Perhaps in early postnatal life, maintenance of critical levels of tactile input of a specific quality and emotional content is important for normal brain maturation. Early somatosensory and social deprivation might produce transneuronal effects on the postnatal development of particular neuronal ensembles not only within the striatum per se but within corticostriatal, basal ganglia-thalamocortical or cerebello-thalamocortical circuits, thereby resulting in altered striatal neurochemistry, impaired sensory information processing, and aberrant behavior. This interpretation is supported by several findings in our study of SD monkeys: (1) loss of TH, calbindin, SP, and LENK immunoreactivity in the striatum; and (2) reduced terminal immunoreactivity for SP and LENK in recipient regions of striatal output neurons (e.g., substantia nigra and globus pallidus) and in recipient regions (e.g., thalamus) of nigral and pallidal projections. We also have preliminary evidence, consistent with preliminary data from other investigators using different experimental conditions (Morrison et al., 1990), suggesting that the density of monoaminergic innervation (fibers and varicosities) is reduced in several cortical areas in SD monkeys. Until 
these studies of cortical changes are complete, we cannot assign a role for them in the social deprivation syndrome. If this hypothesis is correct, there are abundant data linking these regions to aberrant behavior. The striatum is thought to have a critical role in psychomotor behavior, and restricted lesions of the striatum or connectionally related cortical regions produce similar behavioral deficits (Divac and Oberg, 1979). Hence, our results from behaviorally impaired SD monkeys are in concert with other data linking behavioral deficits and impaired integrative functions of interconnected subcortical and cortical systems. However, it is clear that analyses of other brain regions (e.g., neo- and allocortex, thalamus, and cerebellum) in SD monkeys and of the postnatal development of striatal chemoarchitecture and connectivity in SR and SD monkeys would help to clarify the specificity of chemoarchitectonic changes resulting from social deprivation.

\section{Behavior of SD monkeys and possible relationships with chemoarchitectonic changes}

These SD monkeys displayed marked stereotyped and self-injurious behaviors (Lewis et al., 1990) as well as deficits in blocking (Beauchamp et al., 1991). The latter finding (Beauchamp et al., 1991) suggests that SD monkeys develop and maintain an association to an irrelevant stimulus and thus process information inefficiently. Dopaminergic mechanisms have been implicated in stereotypies and self-mutilation (Lewis et al., 1990) and in the capacity to ignore irrelevant or redundant information (Crider et al., 1982). Morenver, SD monkeys show evidence for dopamine receptor supersensitivity (Lewis et al., 1990), and therefore may have long-term alterations in central dopaminergic function (Lewis et al., 1990). Our present immunocytochemical findings support and extend this hypothesis by showing that dopaminergic-neuropeptidergic systems within the striatum are compromised in SD monkeys.

\section{Conclusions}

Few studies have examined neurobiologic effects of social deprivation in primates. Previous studies have shown either no change in monoamine metabolite concentrations in cerebrospinal fluid (Lewis et al., 1990) or significantly increased cerebrospinal fluid concentrations of norepinephrine in SD monkeys following amphetamine administration (Kraemer et al., 1984). The neural mechanisms mediating this change are not clear. This study is the first to document at a cellular level an association between environmental or psychological stress during early development of nonhuman primates and subsequent longterm, regional alterations in neurotransmitter specific systems within the brain. Moreover, this report suggests an important link between abnormalities of the striatal mosaic and aberrant behavior. It also shows that subcortical regions can be highly abnormal chemically but appear unremarkable in common histological preparations. Finally, this study introduces, but leaves unresolved, several questions. Can early social experience shape the postnatal development of striatal structure/function and subsequent behavior in primates? Are there interdependent critical periods in the postnatal ontogeny of specific forebrain regions and in the development of normal socialization?

Our results suggest that early experience can produce multiple, but selective, neurotransmitter changes in specific brain regions and thereby contribute to subsequent behavioral patterns. Systems within the brain that undergo the most postnatal maturation are likely to be the most vulnerable. Conceptually, genetic factors (e.g., neuronal birthdate, migration, and efferent connectivity) would play an important role in prenatal, experienceindependent pattern formation within the striatum. In contrast, environmental factors in early life would have a critical role in postnatal, experience-dependent pattern formation within the striatum. Although distinct periods of cell proliferation and $\mathrm{mi}$ gration and establishment of efferent connectivity contribute to striatal patch and matrix formation (Fishell and van der Kooy, 1987; van der Kooy and Fishell, 1987), the chemical phenotypes and afferents of striatal neurons appear to be partly depcndent upon the social environment experienced by primates during infancy. Moreover, if chemoarchitectonic changes within the basal ganglia correlate with subsequent aberrant behavior, these chemoarchitectonic changes should be gender, time, and species dependent.

Most of the behavioral effects of asocial rearing (Table 1) are more pronounced in males than females (Sackett, 1972b). Furthermore, attempts to induce changes in the postrearing stereotypic and self-directed behaviors of juvenile and adult rhesus monkeys have failed in general (Capitanio, 1986). However, rhesus monkeys that have been reared asocially for 6-12 months and housed subsequently with young infants gradually develop normal social behaviors and a marked reduction in self-directed and stereotyped behavior (Suomi and Harlow, 1972; Novak and Harlow, 1975). Therefore, immutable biological changes have not been induced during 12 months of asocial rearing, and carlicr biological effects can be reversed by intensive therapeutic experiences. In contrast, monkeys that do not receive "therapy" develop the complete spectrum of abnormal behaviors (Table 1), suggesting that associated neural substrates may depend on brain development between infancy and adulthood. Finally, in contrast to the persistent effects of asocial rearing on rhesus monkeys, pig-tailed macaque (Macaca nemastrina) infants, isolated for the first 9 months of life, recover spontaneously after removal from social deprivation (Gluck and Sackett, 1976). The ways in which social deprivation, gender, time, and species interact with neural mechanisms to produce behavioral deficits have implications for pharmacological, environmental, psychological, and social interventions. Because the environment in which development occurs can profoundly influence human behavior (Kolb and Whishaw, 1985), SD monkeys may be an important model for clarifying how carly postnatal social/scnsory distortions and psychological stress during infancy can alter specific neurotransmitter circuits, thereby resulting in stereotypies, self-injurious behaviors, and abnormal social behaviors.

\section{References}

Alexander GE, DeLong MR, Strick PL (1986) Parallel organization of functionally segregated circuits linking basal ganglia and cortex. Annu Rev Neurosci 9:357-381.

Bachevalier J (1990) Development and neural bases of higher cognitive functions (Diamond A, ed), pp 457-477. New York: Academic.

Bachevalier J, Ungerleider LG, O'Neill B, Freidman DP (1986) Regional distribution of $\left[{ }^{3} \mathrm{H}\right]$ naloxone binding in the brain of a newborn rhesus monkey. Dev Brain Res 25:302-308.

Bannon MJ, Lee JM, Giraud P, Young A, Affolter HU, Bonner TI (1986) Dopamine antagonist haloperidol decreases substance $P$, substance $\mathrm{K}$, and preprotachykinin $\mathrm{mRNAs}$ in rat striatonigral neurons. J Biol Chem 261:6640-6642.

Beach TG, McGeer EG (1984) The distribution of substance $P$ in the primate basal ganglia: an immunohistochemical study of baboon and human brain. Neuroscience 13:29-52.

Beauchamp AJ, Gluck JP (1988) Associative processes in differentially reared monkeys (Macaca mulatta): sensory preconditioning. Dev Psychobiol 21:355-364. 
Beauchamp AJ, Gluck JP, Fouty HE, Lewis MII (1991) Associative processes in differentially reared rhesus monkeys (Macaca mulatta): blocking. Dev Psychobiol 24:175-189.

Beckstead RM, Domesick VB, Nauta WJH (1979) Efferent connections of the substantia nigra and ventral tegmental area in the rat. Brain Res 175:191-217.

Berendse HW, Voorn P, de Kortschot A, Groenewegen HJ (1988) Nuclear origin of thalamic afferents of the ventral striatum determines their relation to patch/matrix configurations in enkephalin-immunoreactivity in the rat. J Chem Neuroanat 1:3-10.

Bettler B, Boutler J, Hermans-Borgmeyer I, O'Shea-Greenfield A, Deneris ES, Moll C, Borgmeyer U, Hollmann M, Heinemann S (1990) Cloning of a novel glutamate receptor subunit, GluR5: expression in the nervous system during development. Neuron 5:583-595.

Boylan MK, Levine MS, Buchwald NA, Fisher RS (1990) Patterns of tachykinin expression and localization in developing feline neostriatum. J Comp Neurol 293:151-163.

Capitanio JP (1986) Comparative primate biology (Mitchell G, Erwin J, eds), pp 411-454. New York: Liss.

Celio MR, Norman AW (1985) Nucleus basalis Meynert neurons contain the vitamin D-induced calcium-binding protein (calbindin-D 28k). Anat Embryol 173:143-148.

Cork I.C, Martin I J, Lewis MH, Gluck JP (1990) Early social restriction of rhesus monkeys alters chemoarchitecture in the striatum but not in the bed nucleus-amygdala complex. Soc Neurosci Abstr 16: 442.

Crider A, Solomon PR, McMahon MA (1982) Disruption of selective attention in the rat following chronic $d$-amphetamine administration: relationship to schizophrenic attention disorder. Biol Psychiatry 17: 351-361.

Crutcher MD, DeLong MR (1984) Single cell studies of the primate putamen. Exp Brain Res 53:233-243.

Dearry A, Burnside B (1986) Dopaminergic regulation of cone retinomotor movement in isolated teleost retinas: I. Induction of cone contraction is mediated by $D_{2}$ receptors. J Neurochem 46:1006-1021.

DeLong MR, Hamada I, Alexander GE, Koliatsos V, Martin LJ, Hedreen J (1988) Organization of primate hasal ganglia "motor circuit". 3. relations of striatal microexcitable zones to afferent and efferent projections. Soc Neurosci Abstr 14:721.

de Olmos JS (1990) The human nervous system (Paxinos G, ed), pp 583-710. New York: Academic.

Divac I, Oberg RGE (1979) The neostriatum (Divac I, Oberg RG, eds), pp 215-230. New York: Pergamon.

Fishell G, van der Kooy D (1987) Pattern formation in the striatum: developmental changes in the distribution of striatonigral neurons. $J$ Neurosci 7:1969-1978.

Fittinghoff NA Jr, Lindburg DG, Gomber J, Mitchell G (1974) Consistency and variability in the behavior of mature, isolation-reared, male rhesus macaques. Primates 15:111-139.

Floeter MK, Greenough WT (1979) Cerebellar plasticity: modification of Purkinje cell structure by differential rearing in monkeys. Science 206:227-229.

Frank RG (1979) Assessment of long-term effects of early social isolation: effects of continuous social contact. $\mathrm{PhD}$ thesis, University of New Mexico.

Gerfen CR (1984) The neostriatal mosaic: compartmentalization of corticostriatal input and striatonigral output systems. Nature 311: $461-464$

Gerfen CR (1988) Synaptic organization of the striatum. J Electron Microsc Tech 10:265-281.

Gerfen CR (1990) The neostriatal mosaic: striatal patch-matrix organization is related to cortical lamination. Science 246:385-388.

Gerfen CR, Baimbridge KG, Miller JJ (1985) The neostriatal mosaic: compartmental distribution of calcium-binding protein and parvalbumin in the basal ganglia of the rat and monkey. Proc Natl Acad Sci USA 82:8780-8784.

Gluck JP, Sackett GE (1974) Frustration and self-aggression in social isolate rhesus monkeys. J Abnorm Psychol 83:331-334.

Gluck JP, Sackett GE (1976) Extinction deficits in socially isolated rhesus monkeys (Macaca mulatta). Dev Psychol 12:173-174.

Gluck JP, Harlow HF, Schiltz KA (1973) Differential effect of early enrichment and deprivation on learning in the rhesus monkey $(\mathrm{Ma}$ caca mulatta). J Comp Physiol Psychol 84:598-604.

Gluck JP, Otto MW, Beauchamp AJ (1985) Respondent conditioning of self-injurious behavior in early socially deprived rhesus monkeys. J Abnorm Psychol 94:222-227.
Goldman PS, Nauta WJH (1977) An intricately patterned prefrontocaudate projection in the rhesus monkey. J Comp Neurol 171:369386.

Goosen C (1981) Abnormal behavior patterns in thesus monkeys: symptoms of mental disease? Biol Psychiatry 16:697-716.

Graybiel AM, Chesselet MF (1984) Compartmental distribution of striatal cell bodies expressing [Met]enkephalin-like immunoreactivity. Proc Natl Acad Sci USA 81:7980-7984.

Graybiel AM, Ragsdale CW Jr (1978) Histochemically distinct compartments in the striatum of human, monkey, and cat demonstrated by acetylthiocholinesterase staining. Proc Natl Acad Sci USA 75: 5723-5726.

Graybiel AM, Ragsdale CW Jr (1983) Chemical neuroanatomy (Emson PC, ed), pp 427-504. New York: Raven.

Graybiel AM, Ragsdale CW Jr, Yoneoka ES, Elde RP (1981) An immunohistochemical study of enkephalins and other neuropeptides in the striatum of the cat with evidence that the opiate peptides are arranged to form mosaic patterns in register with the striosomal compartments visible by acetylcholinesterase staining. Neuroscience 6: 377-397.

Griffin GA, Harlow HF (1966) Effects of three months of total social deprivation on social adjustment and learning in the rhesus monkey. Child Dev 37:533-547.

Haber S, Elde R (1982) The distribution of enkephalin immunoreactive fibers and terminals in the monkey central nervous system: an immunohistochemical study. Neuroscience 7:1049-1095.

Haber SN (1986) Neurotransmitters in the human and nonhuman primate basal ganglia. Human Neurobiol 5:159-168.

Hadfield MG, Martin LJ, Price DL (1989) Substance P and neurotensin patterns differ in the primate dorsal and ventral striatum. $J$ Neuropathol Exp Neurol 48:344.

Harlow HF, Harlow MK, Suomi SJ (1971) From thought to therapy: lessons from a primate laboratory. Am Sci 59:538-549.

Hauser KF, McLaughlin PJ, Zagon IS (1987) Endogenous opioids regulate dendritic growth and spine formation in developing rat brain. Brain Res 416:157-161.

Heath RG (1972) Electroencephalographic studies in isolation-raised monkeys with behavioral impairment. Dis Nerv Sys 33:157-163.

Hendry SHC, Jones EG, Burstein N (1988) Activity-dependent regulation of tachykinin-like immunoreactivity in neurons of monkey visual cortex. J Neurosci 8:1225-1238.

Hong JS, Yang HTY, Gillin JC, DiGiulio AM, Fratta W, Costa E (1979) Chronic treatment with haloperidol accelerates the biosynthesis and enkephalins in rat striatum. Brain Res 160:192-195.

Hubel DH (1978) The Harvey lectures, pp 1-51. New York: Academic.

Johnson TN, Rosvold HE, Galkin TW, Goldman PS (1976) Postnatal maturation of subcortical projections from the prefrontal cortex in the rhesus monkey. J Comp Neurol 166:427-444.

King JC, Lechan RM, Kugel G, Anthony ELP (1983) Acrolein: a fixative for immunocytochemical localization of peptides in the central nervous system. J Histochem Cytochem 31:62-68.

Kitt CA, Price DL, Strubel RG, Cork LC, Wainer BH, Becher MW, Mobley WC (1984) Evidence for cholinergic neurites in senile plaques. Science 226:1443-1445.

Kitt CA, Struble RG, Cork LC, Mobley WC, Walker LC, Joh TH, Price DL (1985) Catecholaminergic neurites in senile plaques in prefrontal cortex in aged nonhuman primates. Neuroscience 16:691-699.

Kleinschmidt A, Bear MF, Singer W (1987) Blockade of "NMDA" receptors disrupts experience-dependent plasticity of kitten striate cortex. Science 238:355-358.

Kling A, Green PC (1967) Effects of neonatal amygdalectomy in the maternally reared and maternally deprived macaque. Nature 213: 742-743.

Kolb B, Whishaw IQ (1985) Fundamentals of human neuropsychology, pp 599-630. New York: Freeman.

Kraemer GW (1985) The psychobiology of attachment and separation (Reite M, Field T, eds), pp 135-161. New York: Academic.

Kraemer GW, Ebert MH, Lake CR, McKinney WT (1984) Cerebrospinal fluid measures of neurotransmitter changes associated with pharmacological alteration of the despair response to social separation in rhesus monkeys. Psychiatry Res 11:303-315.

Kubota Y, Inagaki S, Kito S, Takagi H, Smith AD (1986a) Ultrastructural evidence of dopaminergic input to enkephalinergic neurons in rat neostriatum. Brain Res 367:374-378.

Kubota Y, Inagaki S, Kito S (1986b) Innervation of substance P neu- 
rons by catecholaminergic terminals in the neostriatum. Brain Res 375:163-167.

Langer LF, Graybiel AM (1989) Distinct nigrostriatal projection systems innervate striosomes and matrix in the primate striatum. Brain Res 498:344-350.

Lankford KL, DeMello FG, Klein WL (1988) $\mathrm{D}_{1}$-type dopamine receptors inhibit growth cone motility in cultured retina neurons: evidence that neurotransmitters act as morphogenic growth regulators in the developing central nervous system. Proc Natl Acad Sci USA 85:2839-2843.

Lewis MH, Gluck JP, Beauchamp AJ, Keresztury MF, Mailman RB (1990) Long-term effects of early social isolation in Macaca mulatta: changes in dopamine receptor function following apomorphine challenge. Brain Res 513:67-73.

Liozou LA (1972) The postnatal ontogeny of monoamine-containing neurones in the central nervous system of the albino rat. Brain Res 40:395-418.

Lowenstein PR, Slesinger PA, Singer HS, Walker LC, Casanova MF, Raskin LS, Price DL, Coyle JT (1989) Compartment-specific changes in the density of choline and dopamine uptake sites and muscarinic and dopaminergic receptors during the development of the baboon striatum: a quantitative receptor autoradiographic study. J Comp Neurol 288:428-446.

MacLean PD (1990) The triune brain in evolution. New York: Plenum.

Martin L, Lewis M, Gluck J, Cork L (1990) Aberrant compartmental organization of the striatum in isolation reared monkeys. J Neuropathol Exp Neurol 49:284.

Martin LJ, Koliatsos VE, Struble RG, Powers RE, Price DL (1988) Chemoarchitectonic patterns of peptides in human basal forebrain: evidence for a system comprising the bed nucleus, substantia innominata, and central amygdala. Soc Neurosci Abstr 14:671.

Miller RE, Caul WF, Mirsky IA (1971) Patterns of eating and drinking in socially-isolated rhesus monkeys. Physiol Behav 7:127-134.

Missakian EA (1969) Reproductive behavior of socially deprived male rhesus monkeys (Macaca mulatta). J Comp Physiol Psychol 69:403407.

Mitchell G (1970) Primate behavior. Developments in field and laboratory research (Rosenblum LA, ed), pp 195-217. New York: Academic.

Morrison JH, Hof PR, Janssen W, Bassett JL, Foote SL, Kraemer GW, McKinney WT (1990) Quantitative neuroanatomic analyses of cerebral cortex in rhesus monkeys from different rearing conditions. Soc Neurosci Abstr 16:789.

Nastuk MA, Graybicl AM (1989) Ontogeny of $\mathbf{M}_{1}$ and $\mathbf{M}_{2}$ muscarinic binding sites in the striatum of the cat: relationships to one another and to striatal compartmentalization. Neuroscience 33:125-147.

Nishimori T, Buzzi MG, Chudler EH, Poletti CE, Moskowitz MA, Uhl GR (1990) Preproenkephalin upregulation in nucleus caudalis: high and low intensity afferent stimulation differentially modulate early and late responses. J Comp Neurol 302:1002-1018.

Novak MA, Harlow HF (1975) Social recovery of monkeys isolated for the first year of life: I. Rehabilitation and therapy. Dev Psychol 11:353-365.

Olson L, Seiger A, Fuxe K (1972) Heterogeneity of striatal and limbic dopamine innervation: highly fluorescent islands in developing and adult rats. Brain Res 44:283-288.

Pitts DK, Freeman AS, Chiodo LA (1990) Dopamine neuron ontogeny: electrophysiological studies. Synapse 6:309-320.

Prescott JW (1971) Medical primatology 1970. In: Proceedings of the second conference on experimental medical surgery, Primates (Goldsmith EI, Moor-Jankowski J, eds), pp 356-375. Basel: Karger.

Quirion R, Dam TV (1986) Ontogeny of substance P receptor binding sites in rat brain. J Neurosci 6:2187-2199.

Ragsdale CW Jr, Graybiel AM (1988) Fibers from the basolateral nucleus of the amygdala selectively innervate striosomes in the caudate nucleus of the cat. J Comp Neurol 269:506-522.

Riesen AH, Dickerson GP, Struble RG (1977) Tonic functions of sensory systems (Wenzel MB, Zeigler HP, eds), p 285. New York: Academic.

Sackett GP (1972a) Animal models of human behavior (Chauvin R, ed), pp 61-110. Paris: CNRS.

Sackett GP (1972b) Exploratory behavior of rhesus monkcys as a function of rearing experiences and sexes. Dev Psychol 6:260-270.
Schatz CR, Guela C, Morecraft R, Mesulam M-M (1990) Some species differences of the cholinergic basal forebrain in rat and monkey. Soc Neurosci Abstr 16:1095.

Scheel-Kruger J (1986) Dopamine-GABA interactions: evidence that GABA transmits, modulates and mediates dopaminergic functions in the basal ganglia and the limbic system. Acta Neurol Scand [Suppl] 73:1-49.

Sirinathsinghji DJS, Dunnett SB (1989) Disappearance of the $\mu$-opiate receptor patches in the rat neostriatum following lesioning of the ipsilateral nigrostriatal dopamine pathway with 1-methyl-4-phenylpyridinium ion (MPP+): restoration of embryonic nigral dopamine grafts. Brain Res 504:115-120.

Sivam SP, Krause JE (1990) The adaptation of enkephalin, tachykinin and monoamine neurons of the basal ganglia following neonatal dopaminergic denervation is dependent on the extent of dopamine depletion. Brain Res 536:169-175.

Somers DL, Beckstead RM (1990) Striatal preprotachykinin and preproenkephalin mRNA levels and the levels of nigral substance $P$ and pallidal Met $^{5}$-enkephalin depend on corticostriatal axons that use the excitatory amino acid neurotransmitters aspartate and glutamate: quantitative radioimmunocytochemical and in situ hybridization evidence. Mol Brain Res 8:143-158.

Steindler DA, O'Brien TF, Cooper NGF (1988) Glycoconjugate boundaries during early postnatal development of the neostriatal mosaic. J Comp Neurol 267:357-369.

Stevens JR (1973) An anatomy of schizophrenia? Arch Gen Psychiatry 29:177-189.

Struble RG, Riesen AH (1978) Changes in cortical dendritic branching subsequent to partial social isolation in stumptailed monkeys. Dev Psychobiol 11:479-486.

Struble RG, Kitt CA, Walker LC, Cork LC, Price DL (1984) Somatostatinergic neurites in senile plaques of aged non-human primates. Brain Res 324:394-396.

Suomi SJ (1982) Primate behavior (Fobes J, King J, eds), pp 181191. New York: Academic.

Suomi SJ, Harlow HF (1972) Social rehabilitation of isolate-reared monkeys. Dev Psychol 6:487-496.

Tennyson VM, Barrett RE, Cohen G, Cote L, Heikkila R, Mytilineou C (1972) The developing neostriatum of the rabbit: correlation of fluorescence histochemistry, electron microscopy, endogenous dopamine levels, and $\left[{ }^{3} \mathrm{H}\right]$ dopamine uptake. Brain Res 46:251-285.

Tennyson VM, Budininkas-Schoeneheck M, Gershon P (1982) Effects of chronic reserpine treatment on development of maturity of the putamen in fetal rabbits. Brain Res Bull 9:651-662.

Tennyson VM, Gershon P, Budininkas-Schoenebeck M, Rothman TP (1983) Effects of extended periods of reserpine and a-methyl- $p$-tyrosine treatment on the development of the putamen in fetal rabbits. Int J Dev Neurosci 1:305-318.

Tribollet E, Charpak S, Schmidt A, Dubois-Dauphin M, Dreifuss JJ (1989) Appearance and transient expression of oxytocin receptors in fetal, infant, and peripubertal rat brain studies by autoradiography and electrophysiology. J Neurosci 9:1764-1773.

Uhl GR, Navia B, Douglas J (1988) Differential expression of preproenkephalin and preprodynorphin mRNAs in striatal neurons: high levels of preproenkephalin expression depend on cerebral cortical afferents. J Neurosci 8:4755-4764.

Uno H, Tarara R, Else JG, Suleman MA, Sapolsky RM (1989) Hippocampal damage associated with prolonged and fatal stress in primates. J Neurosci 9:1705-1711.

Unterwald EM, Tempel A, Koob GF, Zukin RS (1989) Characterization of opioid receptors in rat nucleus accumbens following mesolimbic dopaminergic lesions. Brain Res 505:111-118.

van der Kooy D, Fishell G (1987) Neuronal birthdate underlies the development of striatal compartments. Brain Res 401:155-161.

Voorn P, Roest G, Groenewegen HJ (1987) Increase of enkephalin and decrease of substance $P$ immunoreactivity in the dorsal and ventral striatum of the rat after midbrain 6-hydroxydopamine lesions. Brain Res 412:391-396.

Young WS, Bonner TI, Braun MR (1986) Mesencephalic dopamine neurons regulate the expression of neuropeptide mRNAs in the rat forebrain. Proc Natl Acad Sci USA 83:9827-9831. 